Article

\title{
Partial Replacement of Dietary Fat with Krill Oil or Coconut Oil Alleviates Dyslipidemia by Partly Modulating Lipid Metabolism in Lipopolysaccharide-Injected Rats on a High-Fat Diet
}

\author{
Hee-Kyoung Son ${ }^{1,+}$, Bok-Hee Kim ${ }^{2,+}$, Jisu Lee ${ }^{1,3}$, Seohyun Park ${ }^{1,3}$, Chung-Bae Oh ${ }^{4}$, Sunyoon Jung ${ }^{1,3} \mathbb{D}$ \\ Jennifer K. Lee ${ }^{5, *(\mathbb{D})}$ and Jung-Heun $\mathrm{Ha}^{1,3, * \mathbb{D}}$
}

check for

updates

Citation: Son, H.-K.; Kim, B.-H.; Lee, J.; Park, S.; Oh, C.-B.; Jung, S.; Lee, J.K.; Ha, J.-H. Partial Replacement of Dietary Fat with Krill Oil or Coconut Oil Alleviates Dyslipidemia by Partly Modulating Lipid Metabolism in Lipopolysaccharide-Injected Rats on a High-Fat Diet. Int. J. Environ. Res. Public Health 2022, 19, 843. https:// doi.org/10.3390/ijerph19020843

Academic Editor: Iñaki Elío

Received: 30 November 2021

Accepted: 8 January 2022

Published: 12 January 2022

Publisher's Note: MDPI stays neutral with regard to jurisdictional claims in published maps and institutional affiliations.

Copyright: (C) 2022 by the authors. Licensee MDPI, Basel, Switzerland. This article is an open access article distributed under the terms and conditions of the Creative Commons Attribution (CC BY) license (https:// creativecommons.org/licenses/by/ $4.0 /)$.
1 Research Center for Industrialization of Natural Neutralization, Dankook University, Cheonan 31116, Korea; kyoung1033@dankook.ac.kr (H.-K.S.); dlwltn970811@naver.com (J.L.); sb5590@naver.com (S.P.); syjung583@dankook.ac.kr (S.J.)

2 Department of Food and Nutrition, Chosun University, Gwangju 61452, Korea; kimbh@chosun.ac.kr

3 Department of Food Science and Nutrition, Dankook University, Cheonan 31116, Korea

4 Office of Technical Liaison, Industry Support Team, Gyeongnam Branch Institute,

Korea Institute of Toxicology, Jinju 52834, Korea; cboh@kitox.re.kr

5 Food Science and Human Nutrition Department, University of Florida, Gainesville, FL 32611, USA

* Correspondence: leejennifer@ufl.edu (J.K.L.); ha@dankook.ac.kr (J.-H.H.)

$\dagger$ These authors contributed equally to this work.

\begin{abstract}
This study investigated the effects of partial replacement of dietary fat with krill oil (KO) or coconut oil (CO) on dyslipidemia and lipid metabolism in rats fed with a high-fat diet (HFD). Sprague Dawley rats were divided into three groups as follows: HFD, HFD + KO, and HFD + CO. The rats were fed each diet for 10 weeks and then intraperitoneally injected with phosphate-buffered saline (PBS) or lipopolysaccharide (LPS) $(1 \mathrm{mg} / \mathrm{kg})$. The KO- and CO-fed rats exhibited lower levels of serum lipids and aspartate aminotransferases than those of the HFD-fed rats. Rats fed with HFD + KO displayed significantly lower hepatic histological scores and hepatic triglyceride (TG) content than rats fed with HFD. The KO supplementation also downregulated the adipogenic gene expression in the liver. When treated with LPS, the HFD + KO and HFD + CO groups reduced the adipocyte size in the epididymal white adipose tissues (EAT) relative to the HFD group. These results suggest that $\mathrm{KO}$ and $\mathrm{CO}$ could improve lipid metabolism dysfunction.
\end{abstract}

Keywords: dyslipidemia; high-fat diet; lipopolysaccharide; krill oil; coconut oil

\section{Introduction}

Over the decades, the prevalence of obesity has dramatically increased in developed and developing countries worldwide [1]. According to recent estimates by the World Health Organization (WHO), more than 1.9 billion adults aged 18 years and older were overweight, and of those, over 650 million were obese [2]. Moreover, the prevalence of obesity in the United States was reported to be 42.4\% in 2017-2018 [3]. If the current trends continue, approximately one in five adults worldwide will be obese by 2025 [4]. Moreover, significant lifestyle changes due to the unexpected coronavirus disease 2019 (COVID-19) pandemic have resulted in a much higher incidence of obesity than expected [5]. Reduced physical activity, increased consumption of high calories (sugar and lipid) and convenience foods, and stress are some significant changes that may contribute to weight gain and obesity [6].

Obesity is caused by the accumulation of body fat when exposed to chronic positive energy balance due to excessive energy intake [7]. Obesity is considered a state of lowgrade systemic inflammation that causes health complications, such as hyperglycemia, 
dyslipidemia, and hypertension [8], and increases the risk of chronic diseases, such as type 2 diabetes (T2D), nonalcoholic fatty liver (NAFLD), and cardiovascular disease (CVD) [9]. Current evidence indicates that lipids, particularly fatty acids (FAs), which comprise a major component of the adipose tissue (AT), play a significant role in the development of obesity and obesity-related metabolic pathogenesis [10,11]. Many studies have reported that the type of fatty acid consumed is more critical than the total fat intake $[12,13]$. The physiological and metabolic effects of fatty acids are determined by types of fatty acids such as saturated, monounsaturated, polyunsaturated, and trans-fatty acids [14]. WHO recommends not to exceed 30\% from total energy intake [15]. Moreover, saturated fatty acids and trans-fatty acids are recommended not to exceed of $10 \%$ and $1 \%$, respectively from total energy intake [16].

Krill oil (KO) is a rich source of omega-3 (n-3) polyunsaturated fatty acids (PUFAs) such as docosahexaenoic acid (DHA) and eicosapentaenoic acid (EPA) [17]. The proportion of $n-3$ PUFAs in KO is approximately $25 \%(w / w)$, where EPA and DHA comprise approximately $14 \%(w / w)$ and $6.5 \%(w / w)$, respectively [18]. $n-3$ PUFAs in KO exist in the form of phospholipids, which possess higher bioavailability and absorption rate compared to fish oil in the form of triacylglycerol $[19,20]$. KO also contains biologically active components, such as astaxanthin and vitamins A and E [21]. Previous studies have reported that these $\mathrm{KO}$ components have various physiological effects, such as anti-hyperlipidemic [22], anti-inflammatory [23], anti-oxidative stress [24], anti-arthritis [25], and neurocognitive improvement [26]. In particular, the anti-obesity effects have been demonstrated to reduce weight gain and improve serum lipid levels in several animal and clinical trials utilizing krill oil supplements [22,27-34]. KO suppressed the expression of proinflammatory mediators and cytokines by inhibiting the phosphorylation of p38 mitogen-activated protein kinase (MAPK) and c-Jun N-terminal kinase (JNK) in lipopolysaccharide (LPS)-stimulated RAW 264.7 macrophages [23].

Medium-chain fatty acids (MCFAs) are fatty acids consisting of 6-12 carbon atoms, and oils such as coconut oil and palm kernel oil are significantly enriched with MCFAs (approximately 55\% of the total fat composition) [35]. Coconut oil (CO) is an edible oil that has gained popularity in recent years and is mainly composed of lauric acid, a mediumchain fatty acid [36,37]. As absorbed in the small intestine and directly transported to the liver by the portal blood system, MCFAs are quickly used as an energy source in the body [38,39]. Dietary MCFAs have been reported to enhance thermogenesis, inhibit fat deposition through fat oxidation, and preserve insulin sensitivity [40]. On the other hand, some studies have claimed that in a typical Western diet, coconut oil consumption causes acute inflammation similar to other SFAs sources [41]. To date, controversy remains regarding the nutritional values and functions of $\mathrm{CO}$.

Administration of LPS, a major component of the outer membrane of Gram-negative bacteria, leads to a rapid and transitory increase in the levels of proinflammatory cytokines such as tumor necrosis factor alpha (TNF- $\alpha$ ) and interleukin (IL)-6 in mammals [42]. As a result, it induces acute inflammation in multiple organs, including the kidney, brain, lung, and liver [43]. Thus, several studies have investigated the anti-inflammatory effects of natural products, compounds, or drugs using LPS-induced animals as models of acute inflammation [44-47]. Recently, we reported that the partial replacement of SFAs in a high-fat diet (HFD) with PUFAs such as perilla oil (PO) or corn oil at a converted dose (2-8\%) suppressed insulin resistance and nuclear factor $\kappa$-light-chain-enhancer of activated B cells (NF- $\mathrm{B}$ ) signaling pathways, and enhanced antioxidant enzyme expression in rats [48]. Intriguingly, we observed that PO and corn oil exacerbated dyslipidemia by elevating triglyceride (TG), total cholesterol (TC), non-high-density lipoprotein-cholesterol (non-HDL-C), aspartate aminotransferase (AST), alanine aminotransferase (ALT), and alkaline phosphatase (ALP) levels when injected with LPS. As n-3 PUFAs are highly prone to oxidation due to their chemical structures, we postulated that these effects might be attributed to oxidative damage and reduced $\alpha$-tocopherol from $n$-3 PUFAs consumption $[49,50]$. To compensate for these adverse effects of n-3 PUFAs previously reported, in this study, we increased the dose of 
$n$-3 PUFAs in $\mathrm{KO}$ by 5\%. As a comparison, HFD was replaced with 5\% MCFAs, as CO was also included in this study. In this study, we investigated the effects of partial replacement of dietary fat with $\mathrm{KO}$ and $\mathrm{CO}$ on metabolic changes induced by LPS administration in HFD-fed rats.

\section{Materials and Methods}

\subsection{Animal Experiments and Diets}

All animal studies were approved by the Dankook University Institutional Animal Care and Use Committee (IACUC, No. DKU-21-051). Five-week-old male Sprague Dawley rats were obtained from the DooYeol Biotech (Seoul, Korea). The KO was obtained from Biocorp (Goheung-gun, Jeollanam-do, Korea), and the CO (Wellspring extra virgin coconut oil, Peter Paul Candy Manufacturing Company, Manila, Philippines) was purchased from a local market in South Korea. A total of 48 rats were housed under a controlled temperature of $22 \pm 1{ }^{\circ} \mathrm{C}$ and humidity of $55 \pm 5 \%$ with a $12 \mathrm{~h}$ light/12 h dark cycle. The experimental rats were randomly assigned to one of the three dietary groups ( $\mathrm{n}=16$ per group): (1) highfat diet (HFD); (2) HFD partially replaced with 5\% krill oil (w/w) (HFD + KO); and (3) HFD partially replaced with $5 \%$ coconut oil $(w / w)(\mathrm{HFD}+\mathrm{CO})$. The dietary composition of HFD, $\mathrm{HFD}+\mathrm{KO}$, and HFD + CO is listed in Table 1. The animals had ad libitum access to the diet and purified water. Following 10 weeks of experimental diet consumption, each group was further divided into two subgroups: (1) an intraperitoneal injection of LPS (1 mg/ kg body weight); or (2) phosphate-buffered saline (PBS) $(1 \mathrm{~mL} / \mathrm{kg}$ body weight). After $24 \mathrm{~h}$ of PBS or LPS injection, the experimental rats were sacrificed by thoracotomy after $\mathrm{CO}_{2}$ narcosis. Blood was collected by cardiac puncture and subsequently centrifuged at $3000 \times \mathrm{g}$ at $4{ }^{\circ} \mathrm{C}$ for $15 \mathrm{~min}$ to isolate the serum. The liver and adipose tissues were harvested and weighed after washing with normal saline solution. The tissues and serum samples were stored at $-80{ }^{\circ} \mathrm{C}$ until further analysis.

Table 1. Composition of the experimental diets.

\begin{tabular}{cccc}
\hline Groups & HFD & HFD + KO & HFD + CO \\
\hline Ingredient (g/kg) & 220 & 220 & 220 \\
Casein & 3.4 & 3.4 & 3.4 \\
L-cysteine & 100 & 100 & 100 \\
Sucrose & 160 & 160 & 160 \\
Corn starch & 155 & 155 & 155 \\
Dextrose & 58 & 58 & 58 \\
Cellulose & 43 & 43 & 43 \\
Mineral mix 1 & 19 & 19 & 19 \\
Vitamin mix ${ }^{2}$ & 2.8 & 2.8 & 2.8 \\
Choline bitartrate & 184 & 134 & 134 \\
Western blend ${ }^{3}$ & 55 & 55 & 55 \\
Lard & 0.034 & 0.034 & 0.034 \\
tert-Butylhydroquinone $_{\text {Krill oil }}$ & & 50 & 50 \\
Coconut oil & & & 4.78 \\
Energy (kcal/g) & 4.78 & 4.78 & $45 \%$ \\
Fat (kcal \%) & $45 \%$ & $45 \%$ & \\
\hline
\end{tabular}

${ }^{1}$ AIN-93-GX, ${ }^{2}$ AIN-93-VX, ${ }^{3}$ Western blend consisting of milk fat, moisture, and milk solid non-fat in a ratio of 82.9:15.7:1.4. Abbreviations: HFD, high-fat diet; HFD + KO, high-fat diet + krill oil; HFD + CO, high-fat diet + coconut oil.

\subsection{Analysis of the Fatty Acid Composition of Experimental Diets}

The fatty acid composition of the experimental diets was determined by methyl esterification of boron trifluoride $\left(\mathrm{BF}_{3}\right)$-methanol [48]. Briefly, $0.1 \mathrm{~g}$ of sample was placed in a test tube, followed by the addition of $0.5 \mathrm{~mL}$ of heptadecanoic acid (C17:0; $1 \mathrm{mg} / \mathrm{mL}$ hexane). $\mathrm{NaOH}$-methanol (2 mL 0.5 N NaOH-methanol) was added to the mixture and heated at $110{ }^{\circ} \mathrm{C}$ for $10 \mathrm{~min}$. After cooling to room temperature, $4 \mathrm{~mL}$ of $\mathrm{BF}_{3}-\mathrm{methanol}$ 
was added to the mixtures and reheated at $110{ }^{\circ} \mathrm{C}$ for $1 \mathrm{~h}$. Thereafter, $2 \mathrm{~mL}$ of hexane was added to the mixture and vortexed for $1 \mathrm{~min}$ to collect the hexane layer for lipid analysis. Fatty acids were analyzed using gas chromatography (GC) (Agilent Technologies $6890 N$, Agilent Technologies, CA, USA). Fatty acids were identified by comparing the peak retention times of those of the reference standard solution Supelco 37-component FAME mix (Sigma-Aldrich Co., St. Louis, MO, USA) and then expressed as a percentage of the total analyzed fatty acids. The fatty acid composition of the experimental diets is shown in Table 2.

Table 2. Fatty acid composition of the experimental diets.

\begin{tabular}{|c|c|c|c|}
\hline \multicolumn{4}{|c|}{ Groups } \\
\hline $\begin{array}{l}\text { Fatty Acid } \\
\text { (\% Total Fatty Acids) }\end{array}$ & HFD & HFD + KO & $\mathrm{HFD}+\mathrm{CO}$ \\
\hline $\mathrm{C}_{4: 0}$, Butyric acid & $0.49 \pm 0.03^{\mathrm{a}}$ & $0.36 \pm 0.02^{b}$ & $0.35 \pm 0.02^{b}$ \\
\hline $\mathrm{C}_{6: 0}$, Caproic acid & $2.08 \pm 0.11^{\mathrm{a}}$ & $1.63 \pm 0.09^{b}$ & $1.69 \pm 0.09^{b}$ \\
\hline $\mathrm{C}_{8: 0}$, Caprylic acid & $1.98 \pm 0.10^{b}$ & $1.67 \pm 0.08^{b}$ & $4.37 \pm 0.22^{\mathrm{a}}$ \\
\hline $\mathrm{C}_{10: 0}$, Capric acid & $4.10 \pm 0.21^{b}$ & $3.19 \pm 0.16^{\mathrm{c}}$ & $4.88 \pm 0.25^{\mathrm{a}}$ \\
\hline $\mathrm{C}_{12: 0}$, Lauric acid & $6.20 \pm 0.31^{b}$ & $4.65 \pm 0.23^{c}$ & $15.91 \pm 0.80^{\mathrm{a}}$ \\
\hline $\mathrm{C}_{13: 0}$, Tridecanoic acid & ND & ND & ND \\
\hline $\mathrm{C}_{14: 0}$, Myristic acid & $11.53 \pm 0.58^{\mathrm{a}}$ & $9.83 \pm 0.50^{b}$ & $12.04 \pm 0.60^{\mathrm{a}}$ \\
\hline $\mathrm{C}_{14: 1}$, Myristoleic acid & $0.76 \pm 0.04^{b}$ & $1.00 \pm 0.05^{\mathrm{a}}$ & $0.76 \pm 0.04^{b}$ \\
\hline $\mathrm{C}_{15: 0}$, Pentadecanoic acid & $1.88 \pm 0.10^{\mathrm{a}}$ & $1.53 \pm 0.08^{b}$ & $1.26 \pm 0.06^{c}$ \\
\hline $\mathrm{C}_{16: 0}$, Palmitic acid & $24.79 \pm 1.24^{\mathrm{a}}$ & $21.97 \pm 1.10^{b}$ & $18.96 \pm 0.95^{c}$ \\
\hline $\mathrm{C}_{16: 1}$, Palmitoleic acid & $2.5 \pm 0.13^{b}$ & $3.78 \pm 0.19^{\mathrm{a}}$ & $2.05 \pm 0.11^{\mathrm{c}}$ \\
\hline $\mathrm{C}_{17: 0}$, Heptadecanoic acid & $2.98 \pm 0.15^{b}$ & $4.31 \pm 0.22^{\mathrm{a}}$ & $3.08 \pm 0.16^{b}$ \\
\hline $\mathrm{C}_{18: 0}$, Stearic acid & $13.5 \pm 0.68^{a}$ & $10.99 \pm 0.55^{b}$ & $11.13 \pm 0.56^{b}$ \\
\hline $\mathrm{C}_{18: 1}$, Oleic acid & $18.23 \pm 0.92$ & $16.64 \pm 0.83$ & $16.32 \pm 0.82$ \\
\hline $\mathrm{C}_{18: 2}$, Linoleic acid & $6.63 \pm 0.33$ & $5.95 \pm 0.30$ & $6.25 \pm 0.32$ \\
\hline $\mathrm{C}_{18: 3}$, Linolenic acid & $1.27 \pm 0.07^{b}$ & $1.68 \pm 0.08^{a}$ & ND \\
\hline $\mathrm{C}_{20: 1}$, Eicosenoic acid & $0.36 \pm 0.02^{b}$ & $0.48 \pm 0.02^{\mathrm{a}}$ & $0.37 \pm 0.02^{b}$ \\
\hline $\mathrm{C}_{20: 2}$, Eicosadienoic acid & $0.29 \pm 0.02^{b}$ & $0.96 \pm 0.05^{\mathrm{a}}$ & $0.27 \pm 0.02^{b}$ \\
\hline $\mathrm{C}_{20: 3}$, Eicosatienoic acid & ND & $0.50 \pm 0.03^{\mathrm{a}}$ & ND \\
\hline $\mathrm{C}_{20: 5}$, Eicosapentaenoic acid & $0.22 \pm 0.01^{b}$ & $5.41 \pm 0.28^{\mathrm{a}}$ & $0.13 \pm 0.01^{b}$ \\
\hline $\mathrm{C}_{22: 1}$, Erucic acid & ND & $0.30 \pm 0.02^{\mathrm{a}}$ & ND \\
\hline$C_{22: 6}$, Docosahexaenoic acid & ND & $3.17 \pm 0.16^{\mathrm{a}}$ & ND \\
\hline Others $^{1}$ & $0.20 \pm 0.01^{\mathrm{a}}$ & ND & $0.18 \pm 0.01^{b}$ \\
\hline SFAs & $69.55 \pm 3.48^{a}$ & $60.14 \pm 3.01^{b}$ & $73.67 \pm 3.69^{a}$ \\
\hline MUFAs & $21.85 \pm 1.10^{\mathrm{ab}}$ & $22.20 \pm 1.11^{\mathrm{a}}$ & $19.50 \pm 0.98^{b}$ \\
\hline PUFAs & $8.41 \pm 0.42^{b}$ & $17.66 \pm 0.89^{\mathrm{a}}$ & $6.65 \pm 0.34^{c}$ \\
\hline$n-6$ & $6.92 \pm 0.35$ & $6.91 \pm 0.35$ & $6.52 \pm 0.33$ \\
\hline$n-3$ & $1.50 \pm 0.08^{b}$ & $10.75 \pm 0.54^{\mathrm{a}}$ & $0.13 \pm 0.01^{\mathrm{c}}$ \\
\hline
\end{tabular}

${ }^{1}$ Others; trans- $C_{18: 1}$, trans- $C_{18: 2}$. Values are expressed as mean \pm standard deviation $(n=3$ per group). Values with different letters are significantly different using the Tukey's multiple comparison post hoc test at $p<0.05$ Abbreviations: HFD, high-fat diet; HFD + KO, high-fat diet + krill oil; HFD + CO, high-fat diet + coconut oil; SFAs, saturated fatty acids; MUFAs, monounsaturated fatty acids; PUFAs, polyunsaturated fatty acids; ND, not detected.

\subsection{Oral Glucose Tolerance Test (OGTT) and Insulin Tolerance Test (ITT)}

The oral glucose tolerance test (OGTT) was performed in experimental rats during the 6 th week of the dietary intervention. Following a $12 \mathrm{~h}$ fast, blood samples were collected by the lateral tail vein incision to determine fasting glucose levels. The rats were then gavaged with a glucose solution ( $1 \mathrm{~g} / \mathrm{kg}$ body weight). Blood glucose level was then analyzed at $0,30,60,90$, and $120 \mathrm{~min}$ after glucose ingestion. Glucose levels were measured using Accu-Chek Instant Test Strips (Accu-Chek, Seoul, Korea) and an Accu-Chek Instant blood glucose meter. The insulin tolerance test (ITT) was conducted at the end (10th week of feeding) of the study. Overnight fasted rats were intraperitoneally injected with insulin at $1 \mathrm{U} / \mathrm{kg}$ body weight. Blood glucose levels were measured at 0, 15, 30, 60, 120, and $210 \mathrm{~min}$ 
during the ITT. Furthermore, glucose and insulin tolerance were evaluated by calculating the area under the curve (AUC) for serum glucose and insulin levels.

\subsection{Analysis of Fatty Acids Composition of Whole Blood}

A drop of whole blood was collected on a blood spot card pretreated with a multicomponent antioxidant cocktail. The blood spot card was purchased from the OmegaQuant Analytics (Sioux Falls, SD, USA), and the blood fatty acid composition was analyzed using GC, as described by Harris and Polreis [51]. The fatty acid composition of whole blood was expressed as a percentage of the total analyzed fatty acids.

\subsection{Determination of Serum Metabolic Parameters}

Serum levels of AST, ALT, ALP, TG, TC, and HDL-C were measured using commercially available kits (MBL, Gunpo, Korea). The non-HDL-C level was calculated by subtracting the HDL-C from the TC. The atherogenic coefficient (AC) was calculated as ((TC - HDL-C) /HDL-C), and cardiac risk factor (CRF) was determined using the following established formula: (TC/HDL-C) [52]. Serum glucose (Crystal Chem, Downers Grove, IL, USA) and insulin (Mercodia AB, Uppsala, Sweden) levels were analyzed using commercial kits according to the manufacturer's instructions. The homeostatic index of insulin resistance (HOMA-IR) values was calculated using the following formula: HOMA-IR = fasting insulin $(\mu \mathrm{U} / \mathrm{mL}) \times$ fasting glucose $(\mathrm{mmol} / \mathrm{L}) / 22.5$ [53].

\subsection{Measurement of Serum IL-1 $\beta$ and MCP-1 Levels}

The serum levels of IL- $1 \beta$ and monocyte chemoattractant protein-1 (MCP-1) were evaluated using a MILLIPLEX map Luminex assay kit (Millipore, Danvers, MA, USA), according to the manufacturer's protocol.

\subsection{Measurement of Lipid Contents in the Liver}

Lipids were extracted from the liver using the method of Bligh and Dyer [54] with slight modifications [48]. Briefly, $0.1 \mathrm{~g}$ of tissue was added to a chloroform/methanol (1:2, $v / v$ ) solution and centrifuged at $1800 \times g$ for $5 \mathrm{~min}$ to obtain the lower lipid layer containing TG and TC for analysis. Subsequently, the TG and TC contents were determined using commercial kits (MBL, Gunpo, Korea).

\subsection{Histological Assessment of the Liver and Epididymal Adipose Tissue}

A portion of the liver and adipose tissue was fixed with a 10-fold volume of $10 \%$ formalin. Thereafter, the tissues were embedded in paraffin blocks and sectioned using a cryo-cut microtome (Leica CM1800, Wetzler, Germany) with a thickness of 3-4 $\mu \mathrm{m}$. The sections were stained with hematoxylin and eosin (H\&E) and captured using an optical microscope (ZEISS Axio Imager 2, Carl Zeiss, Oberkochen, Germany). The liver histological changes were assessed (by a blinded observer) in three different randomly selected 20X fields for each experimental rat. Histological scores were measured using Kleiner's histological scoring system [55] by quantifying the degree of inflammatory cell infiltration, steatosis, and balloon cells. Adipocyte size $\left(\mu \mathrm{m}^{2}\right)$ and the number of crown-like structures (CLS) were determined in three different randomly selected 20X fields for each experimental rat. Adipocyte size and CLS number were measured using an Image J (NIH, Bethesda, MD, USA).

\subsection{Quantitative Real-Time Polymerase Chain Reaction ( $q R T-P C R$ )}

Total RNA was isolated from liver and epididymal adipose tissue using the NucleoZoL reagent (Macherey-Nagel, GmbH \& Co. KG, Düren, Germany). The complementary-DNA (cDNA) was synthesized from $1 \mu \mathrm{g}$ of messenger ribonucleic acid (mRNA) using the iScript $^{\mathrm{TM}} \mathrm{CDNA}$ Synthesis Kit (Bio-Rad Laboratories, CA, USA). The quantitative polymerase chain reaction (qPCR) was performed using the CFX96 Real-Time PCR Detection System (Bio-Rad Laboratories) and conducted using $\mathrm{iQ}^{\mathrm{TM}} \mathrm{SYBR}^{\circledR}$ Green Supermix (Bio-Rad Labo- 
ratories). Quantitative PCR data were evaluated using the comparative critical threshold $(\mathrm{Ct})$ method and were normalized using GAPDH as an internal control (primer sequences are shown in Table 3). Relative gene expression was calculated using the $\Delta \Delta \mathrm{Ct}$ method and expressed as a fold change in the HFD group (PBS group).

Table 3. Primer sequences for quantitative real-time polymerase chain reaction (qRT-PCR).

\begin{tabular}{|c|c|c|}
\hline Gene & & Primer Sequence \\
\hline \multirow{2}{*}{ Il-1 $\beta$} & Forward & 5'-AAA AAT GCC TCG TGC TGT CT-3' \\
\hline & Reverse & $5^{\prime}$-TCG TTG CTT GTC TCT CCT TG-3' \\
\hline \multirow{2}{*}{ CXCL-1 } & Forward & $5^{\prime}$-CCA CAC TCA AGA ATG GTC GC-3' \\
\hline & Reverse & $5^{\prime}$-GTT GTC AGA AGC CAG CGT TC-3' \\
\hline \multirow[b]{2}{*}{ Fas } & Forward & 5'-AAA AGG AAA GTA GAG TGT GC-3' \\
\hline & Reverse & $5^{\prime}$-GAC ACA TTC TGT TCA CTA CAG-3' \\
\hline \multirow{2}{*}{ G6pd } & Forward & $5^{\prime}$-GTT TGG CAG CGG CAA CTA A-3' \\
\hline & Reverse & $5^{\prime}$-GGC ATC ACC CTG GTA CAA CTC-3' \\
\hline \multirow{2}{*}{$\mathrm{C} / \mathrm{EBP}-\alpha$} & Forward & $5^{\prime}$-GCC AAG AAG TCG GTG GAT AA-3' \\
\hline & Reverse & $5^{\prime}$-CGG TCA TTG TCA CTG GTC AA-3' \\
\hline \multirow{2}{*}{ Scd1 } & Forward & $5^{\prime}$-TGT TCG TCA GCA CCT TCT TG-3' \\
\hline & Reverse & $5^{\prime}$-AGT TGA TGT GCC AGC GGT A-3' \\
\hline \multirow{2}{*}{ Acc } & Forward & 5'-CAA CGC CTT CAC ACC ACC TT-3' \\
\hline & Reverse & $5^{\prime}$-AGC CCA TTA CTT CAT CAA AGA TCC T-3' \\
\hline \multirow{2}{*}{ Tgf- $\beta 1$} & Forward & $5^{\prime}$-ACC GAC CCT TCC TGC TCC TCA T-3' \\
\hline & Reverse & $5^{\prime}$-GAT CCA CTT CCA ACC CAG GTC CT-3' \\
\hline \multirow{2}{*}{ Gapdh } & Forward & $5^{\prime}$-CTG TGT CTT TCC GCT GTT TTC-3' \\
\hline & Reverse & 5'-TGT GCT GTG CTT ATG GTC TCA-3' \\
\hline
\end{tabular}

Abbreviations: Il-1 $\beta$, interleukin-1 $\beta$; CXCL-1, C-X-C motif chemokine ligand 1; Fas, fatty acid synthesis; G6pd, glucose-6-phosphate dehydrogenase; C/EBP- $\alpha$, CCAAT enhancer-binding protein $\alpha$; Scd-1, stearoyl-CoA desaturase-1; Acc, acetyl-CoA carboxylase; Tgf-beta 1, transforming growth factor beta 1; Gapdh, glyceraldehyde 3-phosphate dehydrogenase.

\subsection{Statistical Analysis}

Data were presented as means and standard deviations (SDs) or box-and-whisker plots. Two-way analysis of variance (ANOVA) was used to determine the main effects of diet and LPS stimulation or their interactions. Tukey's multiple comparison test was performed when there was a significant interaction between two factors $(p<0.05)$. A summary of the two-way ANOVA results from the main and interaction effects is provided in Table 4. The one-way ANOVA was used to compare the means of the three groups. Differences were considered statistically significant at $p<0.05$. All statistical analyses were performed using XLSTAT 2012 for windows (Addinsoft Inc., Paris, France).

Table 4. Statistical results of the two-way ANOVA for the effect of LPS and diet and LPS X diet interaction.

\begin{tabular}{cccc}
\hline \multirow{2}{*}{ Parameter } & \multicolumn{3}{c}{ Factor, $\boldsymbol{p}$ Values } \\
\cline { 2 - 5 } & LPS & Diet & LPS X Diet \\
\hline $\begin{array}{c}\text { Relative liver and adipose tissue weights } \\
\text { Liver }\end{array}$ & ** $p<0.01$ & $\mathrm{~ns} p=0.931$ & $\mathrm{~ns} p=0.057$ \\
WAT & $\mathrm{ns} p=0.832$ & $* p<0.05$ & $\mathrm{~ns} p=0.884$ \\
EAT & $\mathrm{ns} p=0.509$ & $\mathrm{~ns} p=0.079$ & $\mathrm{~ns} p=0.926$ \\
MAT & $\mathrm{ns} p=0.555$ & $\mathrm{~ns} p=0.265$ & $\mathrm{~ns} p=0.673$ \\
RAT & $\mathrm{ns} p=0.995$ & $* * p<0.01$ & $\mathrm{~ns} p=0.508$ \\
PAT & $\mathrm{ns} p=0.485$ & $\mathrm{~ns} p=0.134$ & $\mathrm{~ns} p=0.925$ \\
\hline
\end{tabular}


Table 4. Cont.

\begin{tabular}{|c|c|c|c|}
\hline \multirow{2}{*}{ Parameter } & \multicolumn{3}{|c|}{ Factor, $p$ Values } \\
\hline & LPS & Diet & LPS X Diet \\
\hline \multicolumn{4}{|l|}{ Serum lipid levels } \\
\hline Triglyceride & $* * p<0.01$ & $* * * * p<0.0001$ & $* * * * p<0.0001$ \\
\hline Total cholesterol & $* * * * p<0.0001$ & ${ }^{*} p<0.05$ & ns $p=0.589$ \\
\hline HDL-cholesterol & ${ }^{* *} p<0.01$ & ns $p=0.095$ & ns $p=0.227$ \\
\hline Non-HDL-cholesterol & $* * * * p<0.0001$ & ${ }^{*} p<0.05$ & ns $p=0.735$ \\
\hline Atherogenic coefficient & $* * * * p<0.0001$ & $* * * p<0.001$ & ns $p=0.997$ \\
\hline Cardiac risk factor & $* * * * p<0.0001$ & $* * * p<0.001$ & ns $p=0.997$ \\
\hline \multicolumn{4}{|l|}{ Serum glucose and insulin levels } \\
\hline Glucose & ns $p=0.782$ & ${ }^{*} p<0.05$ & $* * * p<0.001$ \\
\hline Insulin & ${ }^{*} p<0.05$ & ${ }^{*} p<0.05$ & ${ }^{*} p<0.05$ \\
\hline HOMA-IR & ns $p=0.078$ & ${ }^{*} p<0.05$ & ${ }^{* * *} p<0.001$ \\
\hline \multicolumn{4}{|l|}{ Fatty acid levels in whole blood } \\
\hline $\mathrm{C}_{14: 0}$, Myristic acid & ns $p=0.428$ & ns $p=0.091$ & ns $p=0.658$ \\
\hline $\mathrm{C}_{16: 0}$, Palmitic acid & ns $p=0.199$ & ns $p=0.767$ & ns $p=0.28$ \\
\hline $\mathrm{C}_{16: 1}$, Palmitoleic acid & ns $p=0.311$ & ns $p=0.196$ & ns $p=0.397$ \\
\hline $\mathrm{C}_{18: 0}$, Stearic acid & ns $p=0.643$ & ${ }^{*} p<0.05$ & ns $p=0.35$ \\
\hline $\mathrm{C}_{18: 1}$, Oleic acid & ns $p=0.26$ & ns $p=0.055$ & ns $p=0.353$ \\
\hline $\mathrm{C}_{18: 2}$, Linoleic acid & ns $p=0.908$ & ${ }^{*} p<0.05$ & ns $p=0.105$ \\
\hline $\mathrm{C}_{18: 3 n-3}, \alpha$-linolenic acid & ns $p=0.499$ & ns $p=0.336$ & ns $p=0.636$ \\
\hline $\mathrm{C}_{18: 3 n-6}, \gamma$-linolenic acid & ns $p=0.276$ & ns $p=0.287$ & ns $p=0.195$ \\
\hline $\mathrm{C}_{20: 1}$, Eicosenoic acid & ns $p=0.885$ & ns $p=0.155$ & ns $p=0.700$ \\
\hline $\mathrm{C}_{20: 2,}$ Eicosadienoic acid & ns $p=0.274$ & ns $p=0.23$ & ns $p=0.402$ \\
\hline $\mathrm{C}_{20: 3}$, Dihomo- $\gamma$-linolenic acid & ns $p=0.28$ & ns $p=0.817$ & ${ }^{*} p<0.05$ \\
\hline $\mathrm{C}_{20: 4}$, Aachidonic acid & ns $p=0.941$ & $* * * * 0.001$ & ns $p=0.111$ \\
\hline $\mathrm{C}_{20: 5}$, Eicosapentaenoic acid & ${ }^{*} p<0.05$ & $* * * p<0.001$ & $* p<0.05$ \\
\hline $\mathrm{C}_{22: 4}$, Docosatetraenoic acid & ns $p=0.335$ & $* * * p<0.001$ & ns $p=0.405$ \\
\hline $\mathrm{C}_{22: 5}$, Docosapentaenoic acid & ns $p=0.979$ & $* * * p<0.001$ & ns $p=0.67$ \\
\hline $\mathrm{C}_{22: 6 n-3}$, Docosahexaenoic acid & ${ }^{*} p<0.05$ & $* * * p<0.001$ & ns $p=0.417$ \\
\hline $\mathrm{C}_{22: 6 n-6}$, Docosapentaenoic acid & ns $p=0.716$ & $* * * p<0.001$ & ns $p=0.288$ \\
\hline $\mathrm{C}_{24: 0}$, Lignoceric acid & ns $p=0.504$ & ns $p=0.525$ & ns $p=0.899$ \\
\hline $\mathrm{C}_{24: 1}$, Nervonic acid & ns $p=0.335$ & ${ }^{*} p<0.05$ & ns $p=0.552$ \\
\hline Others & ns $p=0.743$ & $* * p<0.01$ & ns $p=0.29$ \\
\hline SFAs & ns $p=0.169$ & ns $p=0.875$ & ns $p=0.269$ \\
\hline MUFAs & ns $p=0.402$ & ns $p=0.057$ & ns $p=0.356$ \\
\hline PUFAs & ns $p=0.877$ & $* p<0.05$ & ns $p=0.464$ \\
\hline$n-6$ & ns $p=0.904$ & $* * * p<0.001$ & ns $p=0.404$ \\
\hline$n-3$ & ns $p=0.609$ & ${ }^{* * *} p<0.001$ & ns $p=0.891$ \\
\hline$n-6 / n-3$ & ns $p=0.385$ & $* * * 0<0.001$ & ns $p=0.780$ \\
\hline $\mathrm{AA} / \mathrm{EPA}$ & ns $p=0.879$ & $* * * \quad p<0.001$ & ns $p=0.993$ \\
\hline \multicolumn{4}{|l|}{ Serum cytokine levels } \\
\hline IL-1 $\beta$ & ns $p=0.219$ & ${ }^{*} p<0.05$ & ${ }^{*} p<0.05$ \\
\hline MCP-1 & $* * * * p<0.0001$ & ns $p=0.056$ & ns $p=0.338$ \\
\hline \multicolumn{4}{|c|}{ Serum levels of hepatic function parameter } \\
\hline AST & $* * * * p<0.0001$ & $* * * * 0<0.0001$ & ${ }^{*} p<0.05$ \\
\hline ALT & $* * * * p<0.0001$ & $* * p<0.01$ & ns $p=0.357$ \\
\hline ALP & ${ }^{*} p<0.05$ & ns $p=0.958$ & ns $p=0.282$ \\
\hline \multicolumn{4}{|c|}{ Hepatic histology, inflammatory and fibrosis related gene expressions } \\
\hline Hepatic histological score & $* p<0.05$ & ${ }^{* *} p<0.01$ & ns $p=0.357$ \\
\hline TGF- $\beta 1$ mRNA expression & ${ }^{*} p<0.05$ & $* p<0.05$ & ns $p=0.713$ \\
\hline IL-1 $\beta$ mRNA expression & $* * * * * 0.0001$ & ns $p=0.532$ & ns $p=0.461$ \\
\hline CXCL-1 mRNA expression & $* * * p<0.001$ & ns $p=0.263$ & ns $p=0.368$ \\
\hline
\end{tabular}


Table 4. Cont.

\begin{tabular}{|c|c|c|c|}
\hline \multirow{2}{*}{ Parameter } & \multicolumn{3}{|c|}{ Factor, $p$ Values } \\
\hline & LPS & Diet & LPS X Diet \\
\hline \multicolumn{4}{|c|}{ Hepatic lipid level, lipogenesis related gene expressions } \\
\hline Hepatic triglyceride & $* * * * p<0.0001$ & ${ }^{*} p<0.05$ & ns $p=0.733$ \\
\hline Hepatic total cholesterol & $* * * * x<0.0001$ & ns $p=0.168$ & ns $p=0.666$ \\
\hline FAS mRNA expression & ns $p=0.945$ & ns $p=0.466$ & ns $p=0.058$ \\
\hline G6PD mRNA expression & $* p<0.05$ & $* * * * p<0.0001$ & $* * * * * 00.0001$ \\
\hline ACC mRNA expression & $* * * p<0.001$ & ns $p=0.062$ & ns $p=0.341$ \\
\hline C/EBP- $\alpha$ mRNA expression & $* * * * p<0.0001$ & ns $p=0.132$ & $* * p<0.01$ \\
\hline SCD1 mRNA expression & $* * * * \quad p<0.0001$ & $* * p<0.01$ & $* * p<0.01$ \\
\hline \multicolumn{4}{|c|}{ EAT inflammatory and fibrosis related gene expressions } \\
\hline Adipocyte area & ns $p=0.157$ & $* * * p<0.001$ & $* * p<0.01$ \\
\hline Number of CLS & $* * p<0.01$ & ns $p=0.294$ & $* * p<0.01$ \\
\hline IL-1 $\beta$ mRNA expression & $* * * * p<0.0001$ & ns $p=0.485$ & ns $p=0.471$ \\
\hline CXCL-1 mRNA expression & $* * * p<0.001$ & ns $p=0.221$ & ns $p=0.222$ \\
\hline TGF- $\beta 1$ mRNA expression & $* * * * \quad p<0.0001$ & $* * p<0.01$ & ns $p=0.302$ \\
\hline \multicolumn{4}{|c|}{$\begin{array}{l}\text { Ns = not significant; }{ }^{*} p<0.05,{ }^{* *} p<0.01,{ }^{* * *} p<0.001,{ }^{* * * *} p<0.0001 \text {. Abbreviations: WAT, white adipose } \\
\text { tissue; EAT, epididymal adipose tissue; MAT, mesenteric adipose tissue; RAT, retroperitoneal adipose tissue; } \\
\text { PAT, perirenal adipose tissue; HDL, high-density lipoprotein; HOMO-IR, homeostatic model assessment of } \\
\text { insulin resistance; SFAs, saturated fatty acids; MUFAs, monounsaturated fatty acids; PUFAs, polyunsaturated } \\
\text { fatty acids; AA, arachidonic acid; EPA, eicosapentaenoic acid; Acc, acetyl-CoA carboxylase; C/EBP- } \alpha \text {, CCAAT } \\
\text { enhancer-binding protein } \alpha \text {; CXCL-1, C-X-C motif chemokine ligand 1; ALP, alkaline phosphatase; ALT, alanine } \\
\text { aminotransferase; AST, aspartate transaminase; Fas, fatty acid synthesis; G6pd, glucose-6-phosphate dehydroge- } \\
\text { nase; Il-1 } \beta \text {, interleukin- } 1 \text { beta; MCP-1, monocyte chemoattractant protein-1; Scd-1, stearoyl-CoA desaturase-1; } \\
\text { Tgf- } \beta 1 \text {, transforming growth factor beta 1; CLS, crown-like structures. }\end{array}$} \\
\hline
\end{tabular}

\section{Results}

3.1. Effect of the Dietary Fat Replacement with KO or CO on Body Weight Changes, Food Intake, Energy Intake, and Food Efficiency Ratio (FER)

During the experimental period, body weight (BW) did not vary according to dietary intervention (Figure 1a). After seven weeks of experimental feeding, rats fed with HFD + KO diet displayed relatively lower BW; however, BW was not different at other weeks $(p=0.058 \sim 0.194)$. Thus, the daily BW gain is not altered by the various diets (Figure 1b). Intriguingly, the daily food intake of experimental rats fed with $\mathrm{HFD}+\mathrm{KO}$ or $\mathrm{HFD}+\mathrm{CO}$ diet is significantly lower than that of HFD-fed rats (Figure 1c). HFD generally induces excess dietary intake, but dietary fat replacement with PUFAs may decrease overconsuming energy [56]. Due to lower energy intake, HFD + KO- and HFD + CO-fed rats showed elevated FER compared to HFD-fed rats, whereas the difference was not statistically significant (Figure 1d).

\subsection{Effect of the Dietary Fat Replacement with $\mathrm{KO}$ or $\mathrm{CO}$ on Liver and Adipose Tissue Weights}

To determine whether the partial replacement of fat with $\mathrm{KO}$ or $\mathrm{CO}$ affects the weight of the metabolic organs following LPS challenge, the relative weights of the liver, visceral fat depot, and total WAT (WAT; as the sum of the weight of epididymal (EAT), mesenteric (MAT), retroperitoneal (RAT), and perirenal adipose tissue (PAT)) were measured and expressed as a percentage of BW. In the liver, the LPS-treated group showed a significant weight increase (1.1-fold increase; $p<0.01$ ) compared to the PBS-treated group (Figure 2a). Within the PBS-treated group, no differences were observed among the different subgroups; however, rats fed with HFD + KO tended to exhibit lower liver weights compared to those of HFD-fed rats. When stimulated with LPS, the weight of the liver of the different subgroups did not exhibit significant differences. The adipose tissue weights tended to be lower in the HFD + KO group than in the HFD and HFD + CO groups, regardless of the LPS treatment (Figure 2b-f). Furthermore, significant main effects of diets on weights of WAT and RAT using two-way ANOVA were noted in rats fed HFD + KO diets, $p<0.05, p<0.01$, respectively. In summary, these data showed that LPS treatment caused hepatomegaly, 
disregarding the dietary intervention, and the HFD + KO diet may be associated with decreased WAT accumulation.

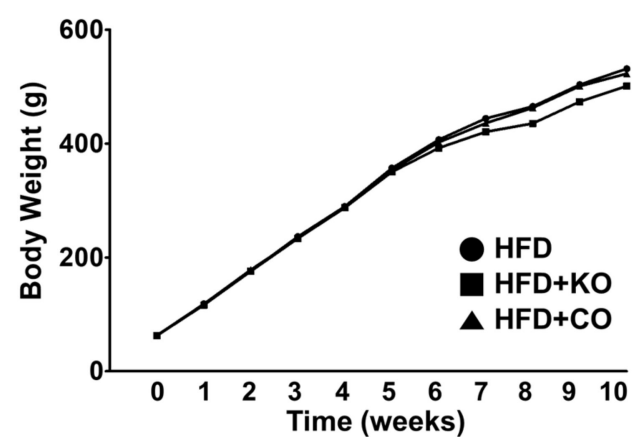

(a)

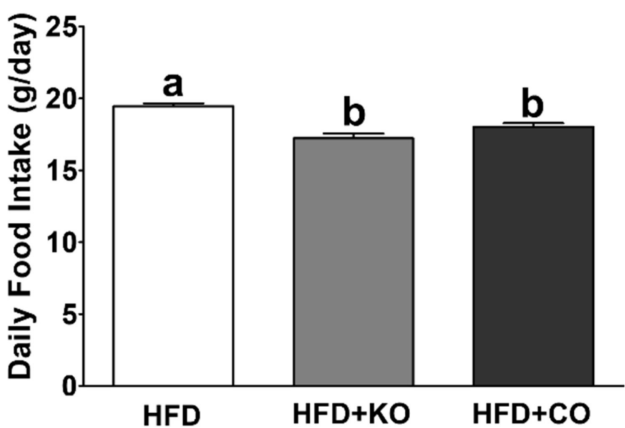

(c)

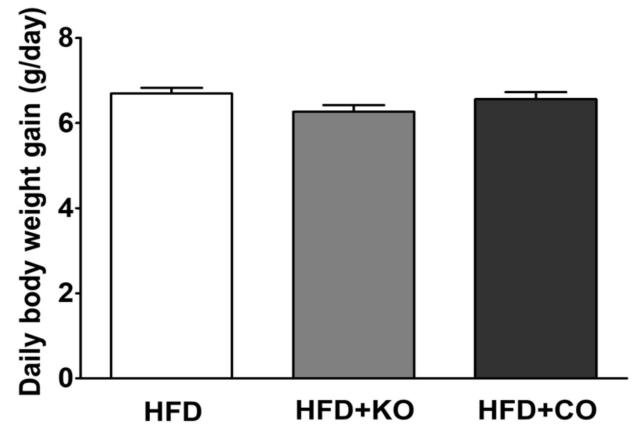

(b)

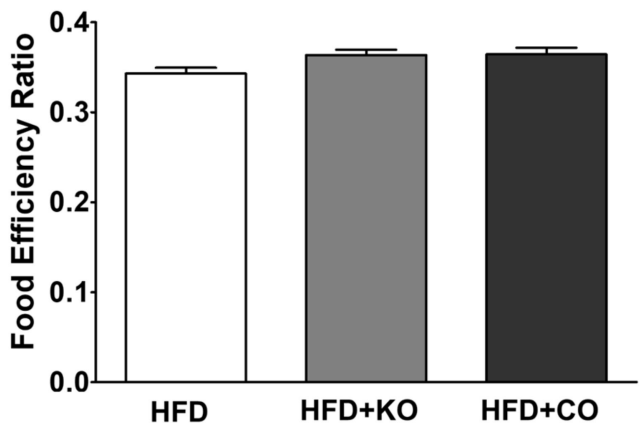

(d)

Figure 1. Effects of partial replacement of dietary fat with krill oil or coconut oil on the body weight, daily body weight gain, food intake, and food efficiency ratio in HFD-fed rats. Sprague Dawley rats were fed either a high-fat diet (HFD; open box), HFD partially replaced with krill oil (HFD + KO; gray-filled box), or coconut oil (HFD + CO; black-filled box) for 10 weeks. (a) Body weight changes, (b) daily body weight gain, (c) daily food intake, and (d) food efficiency ratio (FER) were measured. Values are presented as means $\pm \mathrm{SD} ; \mathrm{n}=16$ per individual group. Data were analyzed using one-way ANOVA followed by Tukey's multiple comparisons test; labeled means without a common letter differ significantly, $p<0.05$. HFD, high-fat diet; HFD $+\mathrm{KO}$, high-fat diet + krill oil; HFD + CO, high-fat diet + coconut oil.

\subsection{Effect of the Dietary Fat Replacement with KO or CO on Serum Lipid Profiles and Cardiovascular Parameters}

To investigate the effects of partial substitution of fat for either $\mathrm{KO}$ or $\mathrm{CO}$ on $\mathrm{CVD}$ prevention and lipid-lowering, we measured the levels of CVD-related serum lipid profiles. After LPS injection, the serum TG, TC, HDL-C, non-HDL-C, AC, and CRF levels remarkably increased by 1.14-, 1.49-, 1.16-, 1.59-, 1.37-, and 1.28-fold, respectively (Figure 3a-f). A significant interaction between LPS and the experimental diet was observed (interaction, $p<0.0001$ ), in which feeding of $\mathrm{KO}$ or $\mathrm{CO}$ remarkably decreased the serum TG levels both in the presence and absence of LPS (Figure 3a). In the vehicle group, serum HDL-C levels were higher in the HFD + KO-or HFD + CO-fed rats than in the HFD-fed rats, whereas the levels in the LPS treatment group were similar among the different dietary groups (Figure 3c). The consumption of HFD + KO or HFD + CO decreased serum non-HDL$\mathrm{C}$ levels compared to the HFD group, regardless of LPS stimulation (Figure $3 \mathrm{~d}$ ). Thus, $\mathrm{KO}$ and CO significantly inhibited the HFD-induced $(p<0.0001)$ and LPS-stimulated $(p<0.001)$ CVD expectancies (atherogenic coefficient and cardiac risk factor) (Figure 3e,f). Cumulatively, these observations indicated that fat replacement with $\mathrm{KO}$ or $\mathrm{CO}$ improved the serum lipid profiles; in particular, $\mathrm{KO}$ had a positive effect on CVD prevention and lipid-lowering, regardless of the LPS challenge. 


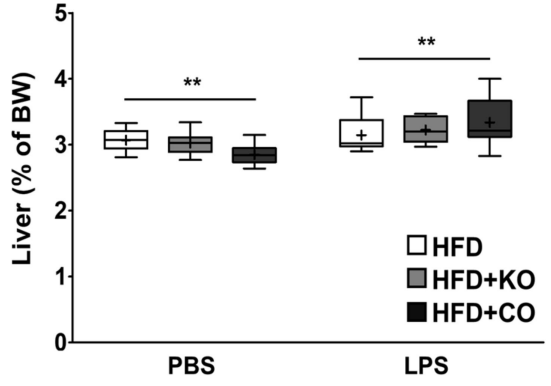

(a)

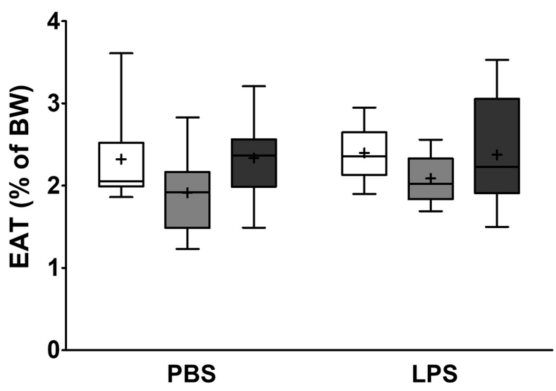

(c)

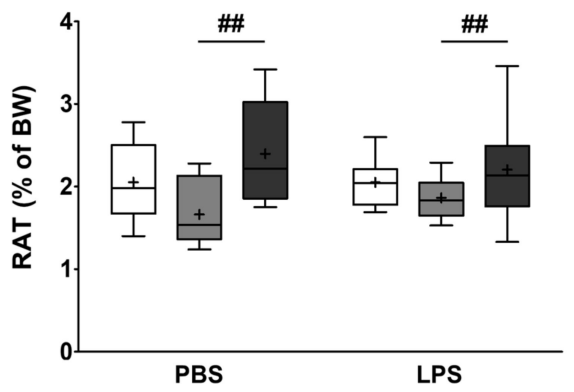

(e)

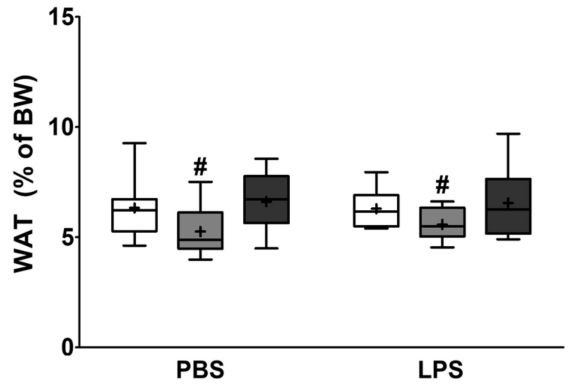

(b)

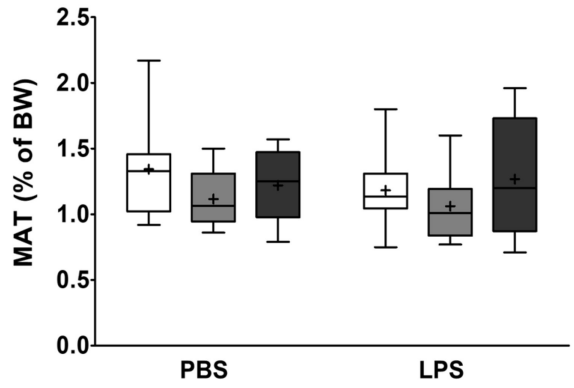

(d)

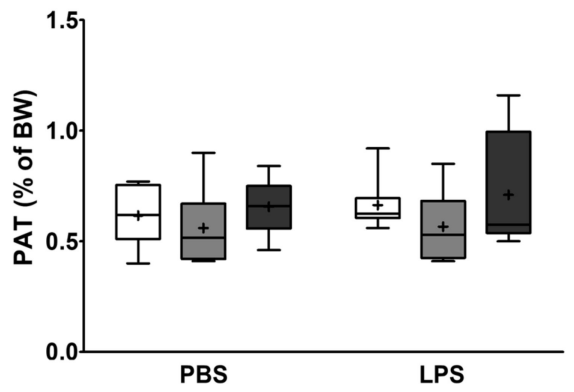

(f)

Figure 2. Effects of partial replacement of dietary fat with krill oil or coconut oil on hepatomegaly and adiposity in rats after the LPS challenge. Sprague Dawley rats were fed either a high-fat diet (HFD), HFD partially replaced with krill oil (HFD + KO), or coconut oil (HFD + CO) for 10 weeks, and then treated with PBS or LPS (1 mg/kg) for $24 \mathrm{~h}$. (a) Liver, (b) total white adipose tissue (WAT), (c) epididymal white adipose tissue (EAT), (d) mesenteric white adipose tissue (MAT), (e) retroperitoneal white adipose tissue (RAT), and (f) perirenal white adipose tissue (PAT) weights were measured. Values are displayed as box-and-whisker plots; $\mathrm{n}=8$ per individual group. Data were analyzed by two-way ANOVA followed by Tukey's multiple comparisons test to determine the interactions or the main effects (diet and LPS stimulation). Asterisk indicates a significant main effect for LPS $\left({ }^{* *} p<0.01\right)$. Pound indicates a significant main effect for $\operatorname{diet}\left({ }^{\#} p<0.05,{ }^{\# \#} p<0.01\right)$. The mean values are indicated by "+" signs. HFD, high-fat diet; HFD + KO, high-fat diet + krill oil; HFD + CO, high-fat diet + coconut oil; PBS, phosphate-buffered saline; LPS, lipopolysaccharide; BW, body weight.

\subsection{Effect of the Dietary Fat Replacement with KO or CO on Oral Glucose Tolerance (OGTT) and} Insulin Tolerance Test (ITT)

During the 6th week of the dietary intervention, OGTT and ITT were performed to determine whether animals consuming HFD + KO or HFD + CO improved glucose utilization, in which FER was increased. Regardless of dietary interventions, blood glucose reached the apex of $30 \mathrm{~min}$ after the glucose challenge; however, HFD + KO cleared blood glucose relatively faster than other experimental groups at $30 \mathrm{~min}$ (Figure $4 \mathrm{a}$ ). Blood glucose levels were not significantly different between the experimental groups at 60 and $120 \mathrm{~min}$. ITT was conducted to understand whether high-fat replacement with $\mathrm{KO}$ or $\mathrm{CO}$ 
might alter insulin resistance (Figure 4c). However, the fat replacement did not change blood glucose levels after insulin injection at $1 \mathrm{mg} / \mathrm{kg} \mathrm{BW}$ for $120 \mathrm{~min}$. The calculated AUC values in the OGTT and ITT did not differ significantly among the experimental diets (Figure $4 b, d$ ). Together, these results indicate that the replacement of fat with $\mathrm{KO}$ or $\mathrm{CO}$ did not affect glucose tolerance or insulin resistance.

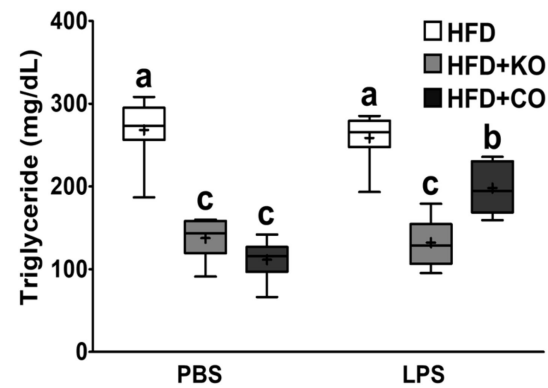

(a)

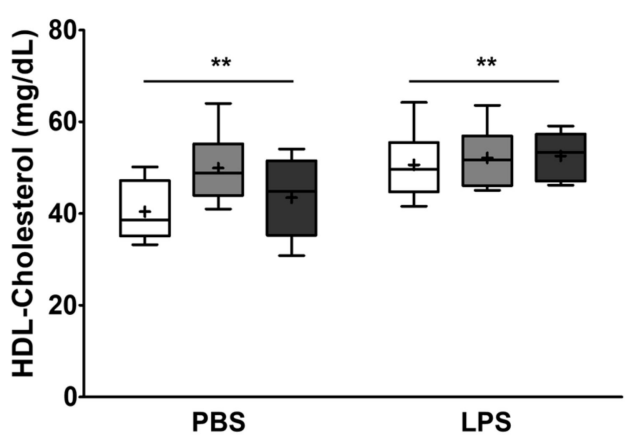

(c)

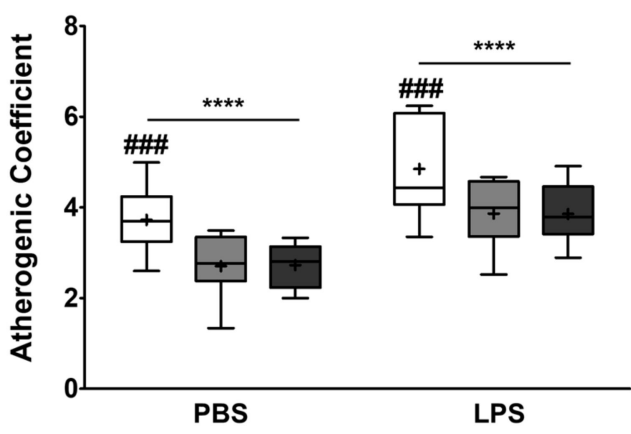

(e)

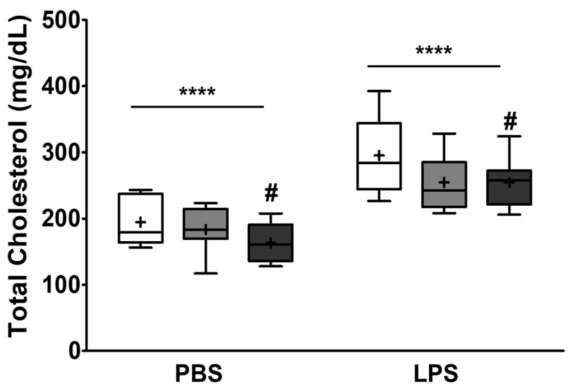

(b)

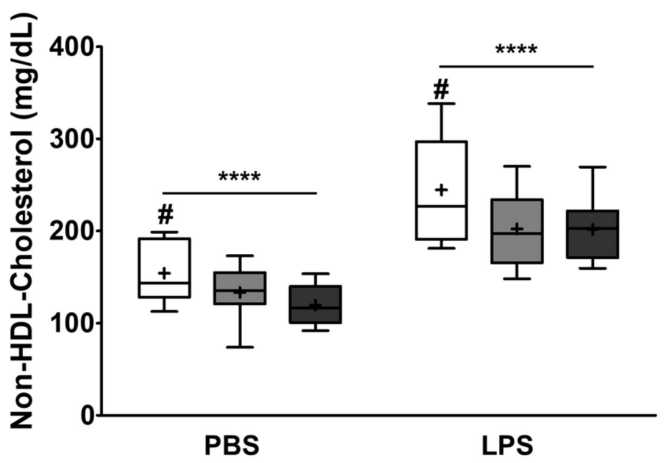

(d)

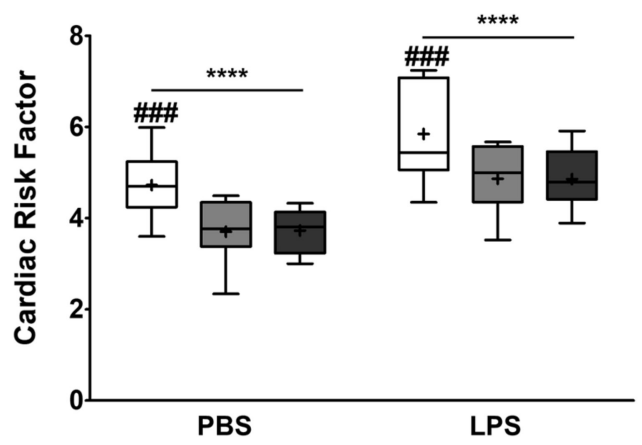

(f)

Figure 3. Effects of partial replacement of dietary fat with krill oil or coconut oil on serum lipid profiles and cardiovascular indices in rats after the LPS challenge. Sprague Dawley rats were fed either a high-fat diet (HFD), HFD partially replaced with krill oil (HFD + KO), or coconut oil $(\mathrm{HFD}+\mathrm{CO})$ for 10 weeks, and then treated with PBS or LPS $(1 \mathrm{mg} / \mathrm{kg})$ for $24 \mathrm{~h}$. (a) Serum triglyceride, (b) total cholesterol, (c) high-density lipoprotein (HDL)-cholesterol, (d) non-HDL cholesterol levels, (e) atherogenic coefficient $(\mathrm{AC})$, and (f) cardiac risk factor (CRF) were measured. Values are displayed as box-and-whisker plots; $\mathrm{n}=8$ per individual group. Data were analyzed by two-way ANOVA followed by Tukey's multiple comparisons test to determine the interactions or the main effects (diet and LPS stimulation. Asterisk indicates a significant main effect for LPS (** $p<0.01,{ }^{* * * *} p<0.0001$ ). Pound indicates a significant main effect for diet $\left({ }^{\#} p<0.05, \# \# p<0.001\right)$. Labeled means without a common letter differ significantly, $p<0.05$. The mean values are indicated by " + " signs. HFD, high-fat diet; HFD + KO, high-fat diet + krill oil; HFD + CO, high-fat diet + coconut oil; PBS, phosphate-buffered saline; LPS, lipopolysaccharide. 


\subsection{Effect of the Dietary Fat Replacement with KO or CO on Serum Glucose and Insulin Levels}

As $\mathrm{KO}$ or $\mathrm{CO}$ consumption remarkably improved HFD-induced and LPS-stimulated serum metabolic parameters, we investigated whether $\mathrm{KO}$ or $\mathrm{CO}$ could also alter insulin, glucose, and HOMA-IR in serum at the end of the dietary intervention. LPS treatment slightly increased serum glucose and insulin levels (only insulin, $p<0.05$; Figure 4e,f). Serum glucose and insulin levels in rats fed with HFD + KO diet in the absence of LPS were significantly lower than those in the HFD group $(p<0.05)$, but they did not decrease in the presence of LPS. Partial replacement of HFD with KO or CO significantly lowered the HOMA-IR index in the PBS group, whereas HFD + CO showed higher levels than those of HFD in the LPS-stimulated group (interaction, $p<0.0001$; Figure 4g).

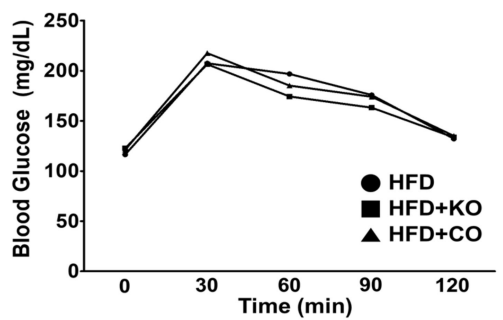

(a)

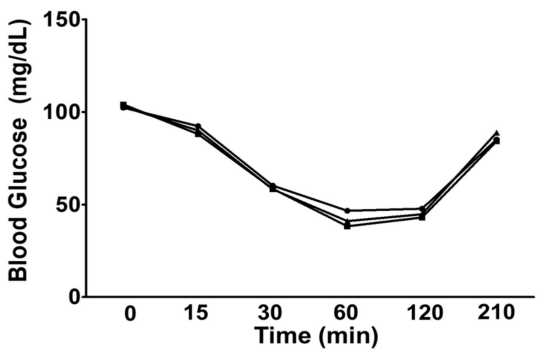

(c)

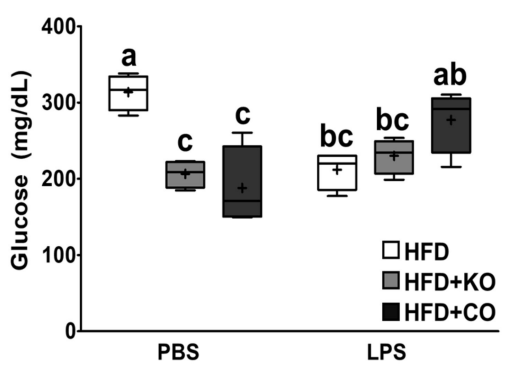

(e)

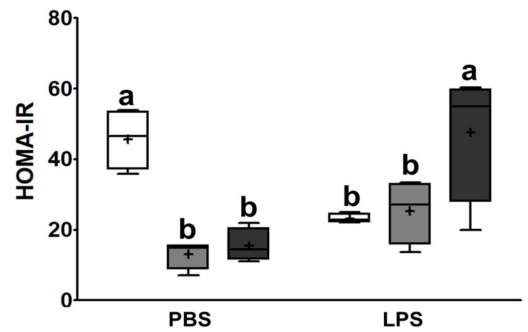

(g)

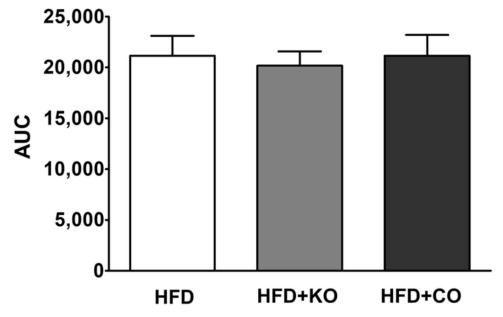

(b)

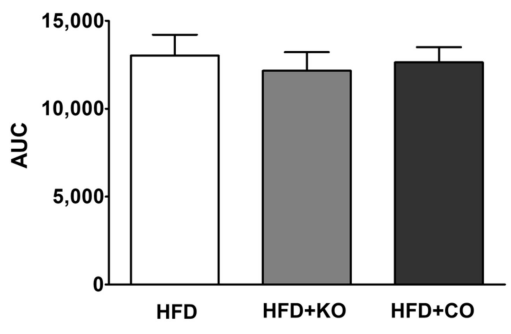

(d)

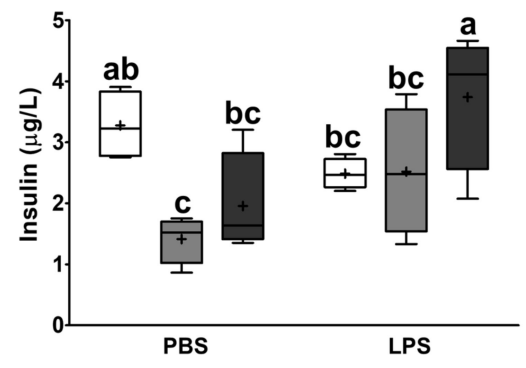

(f)

Figure 4. Effects of partial replacement of dietary fat with krill oil or coconut oil on glucose metabolism in rats. Sprague Dawley rats were fed either a high-fat diet (HFD), HFD partially replaced with krill 
oil (HFD + KO), or coconut oil (HFD + CO) for 10 weeks. (a) Oral glucose tolerance test (OGTT), $\mathrm{n}=16$, (b) the area under the curve (AUC) during OGTT, (c) insulin tolerance test (ITT), $\mathrm{n}=16$, (d) AUC during ITT, (e) serum glucose level, $\mathrm{n}=8$, (f) serum insulin level, $\mathrm{n}=8$, and (g) homeostasis model assessment of insulin resistance (HOMA-IR), $n=8$, were assessed. Data were analyzed by one-way or two-way ANOVA followed by Tukey's multiple comparisons test to determine the interactions or the main effects (diet and LPS stimulation). Labeled means without a common letter differ significantly, $p<0.05$. The mean values are indicated by "+" signs. HFD, high-fat diet; HFD + $\mathrm{KO}$, high-fat diet + krill oil; HFD + CO, high-fat diet + coconut oil; PBS, phosphate-buffered saline; LPS, lipopolysaccharide.

\subsection{Effect of the Dietary Fat Replacement with $\mathrm{KO}$ or $\mathrm{CO}$ on Blood Fatty Acid Composition}

Table 5 shows the changes in fatty acid composition detected in the whole blood of rats. The contents of SFAs and MUFAs in whole blood were not affected by the LPS and dietary interventions. The HFD + KO diet markedly increased the levels of major $n-3$ PUFAs (i.e., EPA, DPA, and DHA), regardless of the LPS challenge $(p<0.001)$. Conversely, rats in the HFD + CO group markedly increased the levels of arachidonic acid (AA), docosatetraenoic acid, docosapentaenoic acid, and total n-6 PUFAs $(p<0.001)$. Consequently, the $n-6 / n-3$ and AA/EPA ratio, a marker of inflammation, were significantly higher in the HFD + CO group than in the other groups, whereas rats fed with HFD + KO diet showed a significant reduction $(p<0.0001)$

Table 5. Effects of partial replacement of dietary fat with krill oil or coconut oil on the fatty acid composition of whole blood in rats after the LPS challenge.

\begin{tabular}{|c|c|c|c|c|c|c|}
\hline \multirow{2}{*}{$\begin{array}{ll}\text { Fatty Acid } & \text { Groups } \\
(\% \text { Total Fatty Acids) } & \\
\end{array}$} & \multicolumn{3}{|c|}{ PBS } & \multicolumn{3}{|c|}{ LPS } \\
\hline & HFD & HFD + KO & $\mathrm{HFD}+\mathrm{CO}$ & HFD & HFD + KO & $\mathrm{HFD}+\mathrm{CO}$ \\
\hline $\mathrm{C}_{14: 0}$, Myristic acid & $1.11 \pm 0.45$ & $0.83 \pm 0.16$ & $1.53 \pm 0.59$ & $0.88 \pm 0.27$ & $0.92 \pm 0.19$ & $1.24 \pm 0.42$ \\
\hline $\mathrm{C}_{16: 0}$, Palmitic acid & $28.47 \pm 0.55$ & $30.5 \pm 0.52$ & $26.9 \pm 0.95$ & $28.07 \pm 0.49$ & $22.43 \pm 11.12$ & $26.57 \pm 0.21$ \\
\hline $\mathrm{C}_{16: 1}$, Palmitoleic acid & $1.17 \pm 0.4$ & $0.74 \pm 0.27$ & $0.80 \pm 0.39$ & $0.84 \pm 0.04$ & $0.85 \pm 0.25$ & $0.61 \pm 0.09$ \\
\hline $\mathrm{C}_{18: 0}$, Stearic acid & $15.17 \pm 1.1$ & $16.57 \pm 0.87$ & $16.97 \pm 0.64$ & $15.77 \pm 0.68$ & $15.83 \pm 0.23$ & $16.57 \pm 0.95$ \\
\hline $\mathrm{C}_{18: 1}$, Oleic acid & $18.03 \pm 3.40$ & $14.67 \pm 1.45$ & $13.93 \pm 2.03$ & $17.37 \pm 1.05$ & $15.9 \pm 0.20$ & $16.4 \pm 0.92$ \\
\hline $\mathrm{C}_{18: 2,}$, Linoleic acid & $7.70 \pm 1.08$ & $7.92 \pm 0.50$ & $7.82 \pm 0.63$ & $6.66 \pm 0.64$ & $8.39 \pm 0.73$ & $8.51 \pm 0.43$ \\
\hline $\mathrm{C}_{18: 3 n-3}, \alpha$-linolenic acid & $0.15 \pm 0.11$ & $0.06 \pm 0.05$ & $0.10 \pm 0.06$ & $0.11 \pm 0.12$ & $0.09 \pm 0.03$ & $0.05 \pm 0.02$ \\
\hline $\mathrm{C}_{18: 3 n-6}, \gamma$-linolenic acid & $0.05 \pm 0.02$ & $0.03 \pm 0.02$ & $0.08 \pm 0.05$ & $0.04 \pm 0.02$ & $0.04 \pm 0.01$ & $0.04 \pm 0.01$ \\
\hline $\mathrm{C}_{20: 1}$, Eicosenoic acid & $0.18 \pm 0.01$ & $0.10 \pm 0.06$ & $0.12 \pm 0.04$ & $0.16 \pm 0.12$ & $0.09 \pm 0.06$ & $0.16 \pm 0.02$ \\
\hline $\mathrm{C}_{20: 2}$, Eicosadienoic acid & $0.32 \pm 0.12$ & $0.18 \pm 0.07$ & $0.26 \pm 0.08$ & $0.20 \pm 0.07$ & $0.18 \pm 0.06$ & $0.24 \pm 0.07$ \\
\hline $\mathrm{C}_{20: 3}$, Dihomo- $\gamma$-linolenic acid & $0.65 \pm 0.07^{\mathrm{a}}$ & $0.55 \pm 0.08^{a b}$ & $0.58 \pm 0.11^{\mathrm{ab}}$ & $0.50 \pm 0.05^{b}$ & $0.63 \pm 0.04^{\mathrm{a}}$ & $0.55 \pm 0.04^{\mathrm{ab}}$ \\
\hline $\mathrm{C}_{20: 4}$, Aachidonic acid & $20.00 \pm 2.25$ & $11.00 \pm 0.92$ & $23.7 \pm 1.06$ & $21.73 \pm 1.19$ & $11.00 \pm 0.20$ & $22.10 \pm 0.95$ \\
\hline $\mathrm{C}_{20: 5}$, Eicosapentaenoic acid & $0.36 \pm 0.12^{c}$ & $7.58 \pm 0.48^{\mathrm{a}}$ & $0.22 \pm 0.06^{c}$ & $0.39 \pm 0.12^{c}$ & $6.64 \pm 0.48^{b}$ & $0.20 \pm 0.03^{c}$ \\
\hline $\mathrm{C}_{22: 4}$, Docosatetraenoic acid & $0.89 \pm 0.24$ & $0.09 \pm 0.06$ & $1.57 \pm 0.37$ & $0.89 \pm 0.07$ & $0.08 \pm 0.02$ & $1.3 \pm 0.11$ \\
\hline $\mathrm{C}_{22: 5}$, Docosapentaenoic acid & $1.27 \pm 0.29$ & $3.47 \pm 0.64$ & $1.22 \pm 0.17$ & $1.2 \pm 0.46$ & $3.67 \pm 0.1$ & $1.07 \pm 0.14$ \\
\hline $\mathrm{C}_{22: 6 n-3}$, Docosahexaenoic acid & $2.57 \pm 0.41$ & $3.97 \pm 0.74$ & $2.11 \pm 0.25$ & $3.1 \pm 0.42$ & $4.89 \pm 0.51$ & $2.31 \pm 0.21$ \\
\hline$C_{22: 6 n-6}$, Docosapentaenoic acid & $0.24 \pm 0.07$ & $0.02 \pm 0.01$ & $0.66 \pm 0.18$ & $0.35 \pm 0.06$ & $0.06 \pm 0.01$ & $0.57 \pm 0.17$ \\
\hline $\mathrm{C}_{24: 0}$, Lignoceric acid & $0.32 \pm 0.09$ & $0.36 \pm 0.23$ & $0.37 \pm 0.04$ & $0.26 \pm 0.04$ & $0.35 \pm 0.05$ & $0.33 \pm 0.05$ \\
\hline $\mathrm{C}_{24: 1}$, Nervonic acid & $0.21 \pm 0.05$ & $0.29 \pm 0.09$ & $0.11 \pm 0.03$ & $0.12 \pm 0.11$ & $0.23 \pm 0.15$ & $0.13 \pm 0.03$ \\
\hline Others ${ }^{1}$ & $0.28 \pm 0.02$ & $0.20 \pm 0.05$ & $0.21 \pm 0.04$ & $0.23 \pm 0.05$ & $0.16 \pm 0.02$ & $0.16 \pm 0.04$ \\
\hline SFAs & $45.07 \pm 1.27$ & $48.26 \pm 1.57$ & $45.76 \pm 1.1$ & $44.97 \pm 0.68$ & $39.54 \pm 11.38$ & $44.7 \pm 1.29$ \\
\hline MUFAs & $19.6 \pm 3.76$ & $15.79 \pm 1.67$ & $14.96 \pm 2.37$ & $18.48 \pm 1.08$ & $17.07 \pm 0.53$ & $17.3 \pm 1.01$ \\
\hline PUFAs & $34.2 \pm 2.79$ & $34.86 \pm 2.29$ & $38.31 \pm 1.63$ & $35.17 \pm 1.26$ & $35.68 \pm 0.84$ & $36.92 \pm 1.15$ \\
\hline$n-6$ & $29.85 \pm 2.42$ & $19.79 \pm 0.63$ & $34.66 \pm 1.69$ & $30.37 \pm 0.51$ & $20.38 \pm 0.68$ & $33.3 \pm 1.23$ \\
\hline$n-3$ & $4.35 \pm 0.45$ & $15.07 \pm 1.67$ & $3.65 \pm 0.15$ & $4.8 \pm 0.75$ & $15.29 \pm 0.94$ & $3.62 \pm 0.08$ \\
\hline$n-6 / n-3$ & $6.88 \pm 0.48$ & $1.32 \pm 0.11$ & $9.51 \pm 0.72$ & $6.43 \pm 0.98$ & $1.34 \pm 0.11$ & $9.21 \pm 0.53$ \\
\hline $\mathrm{AA} / \mathrm{EPA}$ & $58.24 \pm 12.03$ & $1.45 \pm 0.06$ & $\begin{array}{c}112.14 \pm \\
27.47\end{array}$ & $59.25 \pm 17.89$ & $1.66 \pm 0.15$ & $\begin{array}{c}114.63 \pm \\
21.89\end{array}$ \\
\hline
\end{tabular}

${ }^{1}$ Others; trans- $C_{16: 1}$, trans- $C_{18: 1}$, trans- $C_{18: 2}$. Values are presented as the mean \pm standard deviation $(n=3$ per group). Data are analyzed by two-way ANOVA followed by Tukey's multiple comparisons test to determine the interactions or the main effects (diet and LPS stimulation). Abbreviations: HFD, high-fat diet; HFD + KO, high-fat diet + krill oil; HFD + CO, high-fat diet + coconut oil; PBS, phosphate-buffered saline; LPS, lipopolysaccharide SFAs, saturated fatty acids; MUFAs, monounsaturated fatty acids; PUFAs, polyunsaturated fatty acids; AA, arachidonic acid; EPA, eicosapentaenoic acid. 
3.7. Effect of the Dietary Fat Replacement with KO or CO on Serum Proinflammatory Cytokines, and Chemokine Levels

To explore the effects of fat replacement with $\mathrm{KO}$ or $\mathrm{CO}$ on proinflammatory status, the serum levels of cytokines and chemokines, such as IL-1 $\beta$ and MCP-1, were evaluated. Although LPS stimulation tended to increase IL-1 $\beta$ but did not reach statistical significance $(p=0.219)$, the MCP-1 levels significantly increased by 3.83-fold $(p<0.0001$; Figure $5 \mathrm{a}, \mathrm{b})$. The IL- $1 \beta$ levels in rats fed with HFD + CO following LPS stimulation were significantly higher than those in other groups (interaction, $p<0.05$ ). Interestingly, in the LPS-stimulated group, higher MCP-1 levels were observed in the HFD + KO group than in the HFD group, but the difference was not significant.

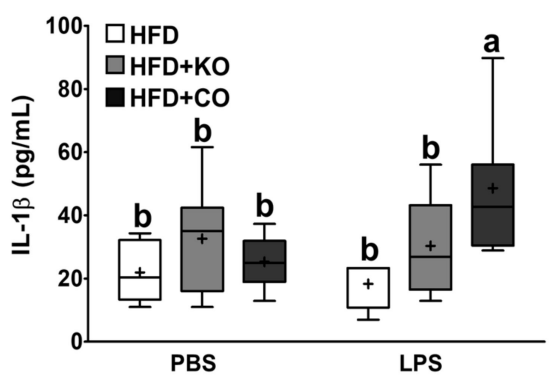

(a)

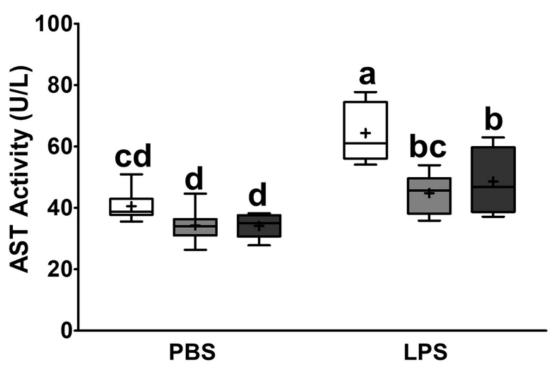

(c)

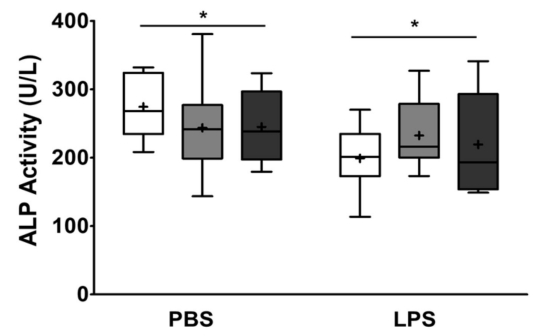

(e)

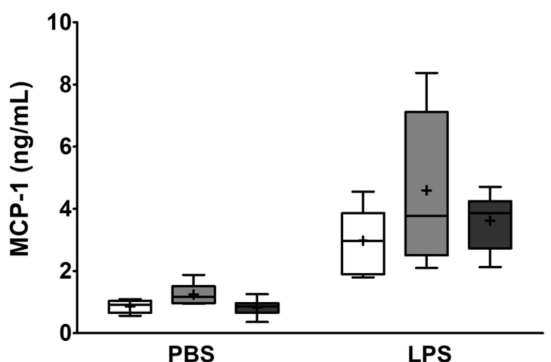

(b)

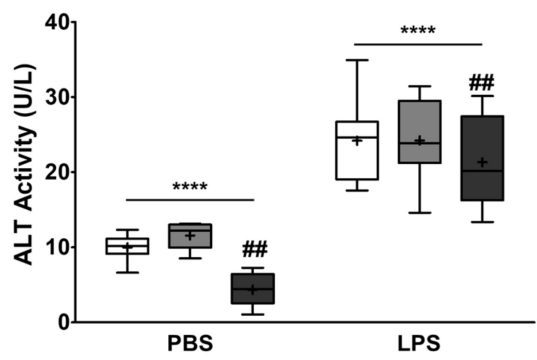

(d)

Figure 5. Effects of partial replacement of dietary fat with krill oil or coconut oil on serum proinflammatory cytokines, chemokine, and hepatic function enzyme levels in rats after the LPS challenge. Sprague Dawley rats were fed either a high-fat diet (HFD), HFD partially replaced with krill oil (HFD $+\mathrm{KO})$, or coconut oil (HFD + CO) for 10 weeks, and then treated with PBS or LPS $(1 \mathrm{mg} / \mathrm{kg})$ for 24 h. (a) Interleukin (IL)-1 $\beta$ levels, (b) monocyte chemoattractant protein (MCP)-1 levels, (c) aspartate aminotransferase (AST), (d) alanine aminotransferase (ALT), and (e) alkaline phosphatase (ALP) activities were analyzed. Values are displayed as box-and-whisker plots, $n=8$ per individual group Data were analyzed by two-way ANOVA followed by Tukey's multiple comparisons test to determine the interactions or the main effects (diet and LPS stimulation). Asterisk indicates a significant main effect for LPS $\left.{ }^{*} p<0.05,{ }^{* * * *} p<0.0001\right)$. Pound indicates a significant main effect for diet $\left.{ }^{\# \#} p<0.01\right)$. Labeled means without a common letter differ significantly, $p<0.05$. The mean values are indicated by "+" signs. HFD, high-fat diet; HFD + KO, high-fat diet + krill oil; HFD + CO, high-fat diet + coconut oil; PBS, phosphate-buffered saline; LPS, lipopolysaccharide. 


\subsection{Effect of the Dietary Fat Replacement with KO or CO on Enzyme Profiles Related to Hepatic Function}

To investigate the effects of partial replacement of fat with $\mathrm{KO}$ or $\mathrm{CO}$ on hepatic damage, we measured the activity of enzyme markers (ALT, AST, and ALP) of hepatic function following the LPS challenge. Changes in hepatic function enzymes in the serum are shown in Figure $5 \mathrm{c}-\mathrm{e}$. Compared to the PBS group, LPS injection markedly enhanced serum AST and ALT activities by 1.45 -fold and 2.69 -fold, respectively $(p<0.0001)$, but significantly decreased ALP activity. Serum AST activity was significantly lower in KOor CO-fed rats in the PBS group than in rats fed with HFD + CO with LPS stimulation. Serum ALT activity was similar between the HFD and HFD + KO groups, whereas the HFD + CO group had lower activity than the other groups. Serum ALP activity of rats fed diets supplemented with $\mathrm{KO}$ or $\mathrm{CO}$ in the PBS group tended to be lower than that in the HFD group. Although the LPS group tended to increase serum ALP activity by KO or CO feeding, the dietary intervention did not affect serum ALP activity.

\subsection{Effect of the Dietary Fat Replacement with $\mathrm{KO}$ or $\mathrm{CO}$ on Hepatotoxicity and Hepatic Fibrosis}

Rats fed with HFD displayed degenerative changes in the hepatocytes with inflammatory cell infiltration and ballooning cell necrosis around the central vein area compared to the HFD + KO or HFD + CO groups (Figure 6a). Interestingly, the histological changes in the HFD + KO-supplemented rats were remarkably attenuated regardless of the LPS challenge. Consequently, inflammatory cells, steatosis, and hepatocellular ballooning in the liver were assessed and graded numerically (Figure 6b). The liver histological score was $42.27 \%$ and $11.36 \%$, which was lower in rats fed with HFD or HFD + CO diet, respectively, compared to the HFD group $(p<0.01)$. These data suggest that fatty acid replacement with $\mathrm{KO}$ or $\mathrm{CO}$ resulted in reduced hepatic damage with improved liver function and lipid accumulation, regardless of the LPS challenge. The fibrosis-marker TGF- $\beta 1$ expression was significantly decreased $(p<0.05)$ in the presence of LPS. Furthermore, the HFD + KO-fed rats showed lower TGF- $\beta 1$ expression than the other experimental groups $(p<0.05$, Figure $6 c$ ). The IL-1 $\beta$ and C-X-C motif chemokine ligand 1 (CXCL-1) levels in the liver were significantly upregulated by 7.88-fold and 6.10-fold, respectively, following LPS stimulation (Figure 6d,e) $(p<0.0001$; IL-1 $\beta, p<0.01$; CXCL-1). The expression of CXCL-1 in the liver of rats fed with HFD $+\mathrm{KO}$ or HFD $+\mathrm{CO}$ in the LPS group tended to be lower than that in the HFD group.

\subsection{Effect of the Dietary Fat Replacement with KO or CO on Fat Accumulation and mRNA Expression of Lipogenesis-related Genes in the Liver}

Moreover, we measured the hepatic lipid levels, as shown in Figure 7a,b. Hepatic TG and TC levels were significantly reduced following the LPS challenge $(p<0.0001)$. Rats fed with HFD + KO had substantially lower hepatic TG levels than those in the HFD and HFD + CO groups $(p<0.05)$. However, hepatic TC levels did not vary considerably with dietary intervention (Figure 7b). LPS challenge decreased the hepatic glucose-6-phosphate dehydrogenase (G6PD), acetyl-CoA carboxylase (ACC), CCAAT enhancer-binding protein $\alpha(\mathrm{C} / \mathrm{EBP}-\alpha)$, and stearoyl-CoA desaturase-1 (SCD1) mRNA expression by $18.24 \%, 49.19 \%$, $66.04 \%$, and $71.59 \%$, respectively (Figure $7 \mathrm{~d}-\mathrm{g}$ ). Prior to LPS treatment, fatty acid synthesis (FAS), G6PD, and ACC mRNA expression was decreased in the HFD + KO and HFD + CO groups compared to the HFD group (Figure 7c-e). However, following LPS treatment, FAS, $\mathrm{C} / \mathrm{EBP}-\alpha$, and SCD1 mRNA expression were not altered by the HFD + KO and HFD + CO diets (Figure 7c,f,g). 


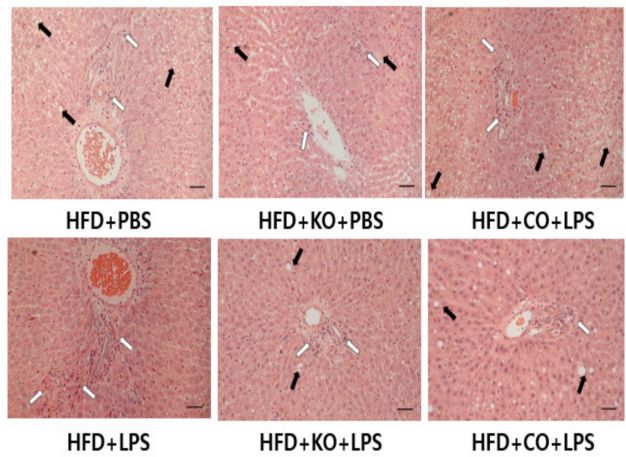

(a)

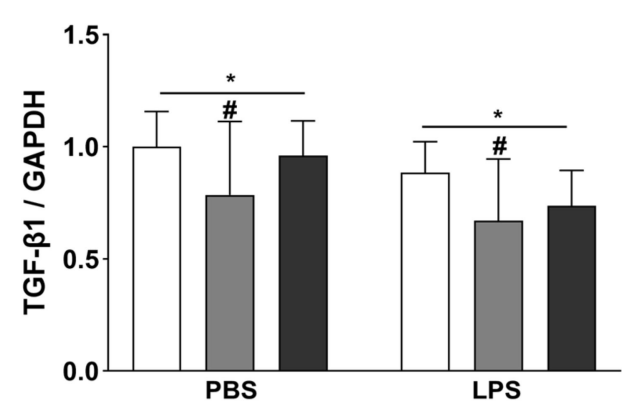

(c)

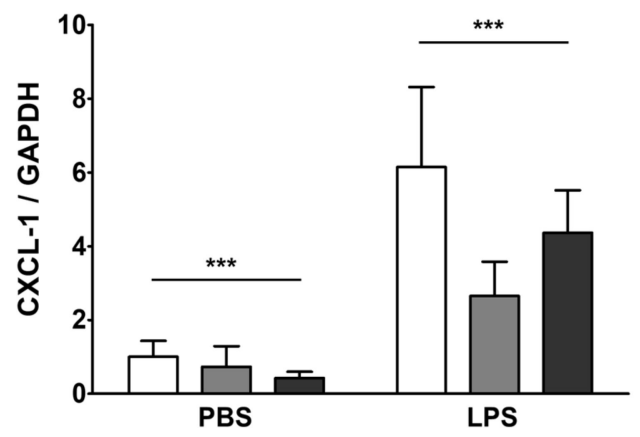

(e)

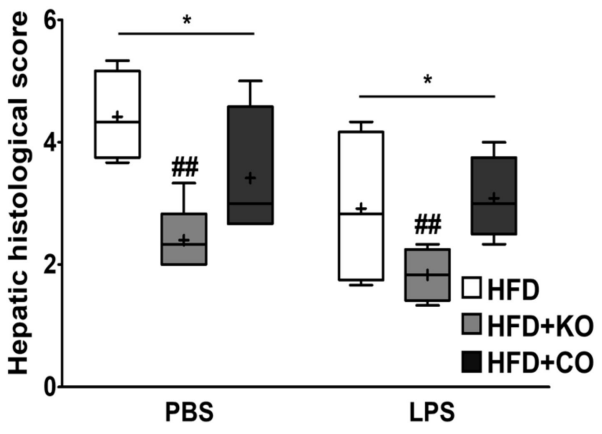

(b)

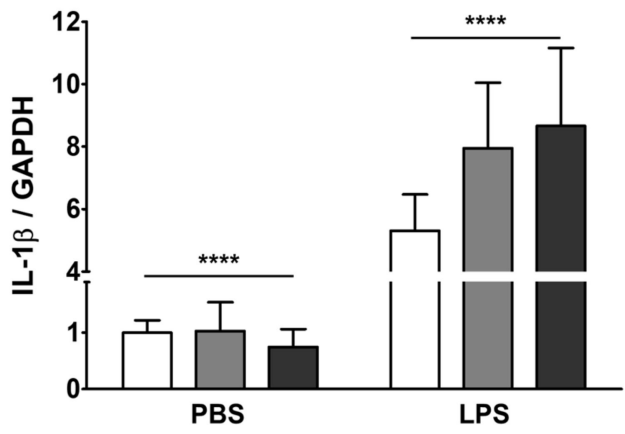

(d)

Figure 6. Effects of partial replacement of dietary fat with krill oil or coconut oil on the hepatic histopathology, and mRNA expression of proinflammatory genes in rats after the LPS challenge. Sprague Dawley rats were fed either a high-fat diet (HFD), HFD partially replaced with krill oil (HFD $+\mathrm{KO})$, or coconut oil (HFD + CO) for 10 weeks, and then treated with PBS or LPS $(1 \mathrm{mg} / \mathrm{kg})$ for $24 \mathrm{~h}$. (a) Hematoxylin and eosin (H\&E) staining of liver tissue (bar $=50 \mu \mathrm{m}, 20 \times$ magnification); black arrow indicates lipid accumulation and white arrow indicates inflammatory foci. (b) hepatic histological score, (c) transforming growth factor- $\beta 1$ (TGF- $\beta 1$ ), (d) interleukin 1 beta (IL-1 $\beta$ ) level, and (e) chemokine (C-X-C motif) ligand 1 (CXCL-1) mRNA expression levels were assessed. Values are displayed as box-and-whisker plots, $\mathrm{n}=8$ per individual group. Data were analyzed by two-way ANOVA followed by Tukey's multiple comparisons test to determine the interactions or the main effects (diet and LPS stimulation). Asterisk indicates a significant main effect for LPS $(* p<0.05$, $\left.{ }^{* * *} p<0.001,{ }^{* * * *} p<0.0001\right)$. Pound indicates a significant main effect for $\operatorname{diet}\left({ }^{\#} p<0.05,{ }^{\# \#} p<0.01\right)$. The mean values are indicated by "+" signs. HFD, high-fat diet; HFD + KO, high-fat diet + krill oil; HFD + CO, high-fat diet + coconut oil; PBS, phosphate-buffered saline; LPS, lipopolysaccharide. 


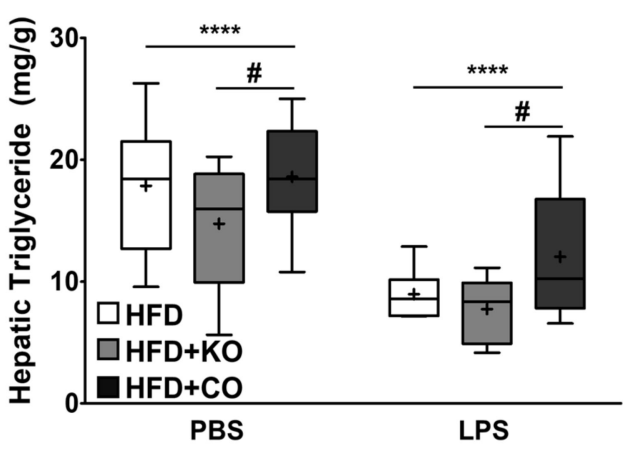

(a)

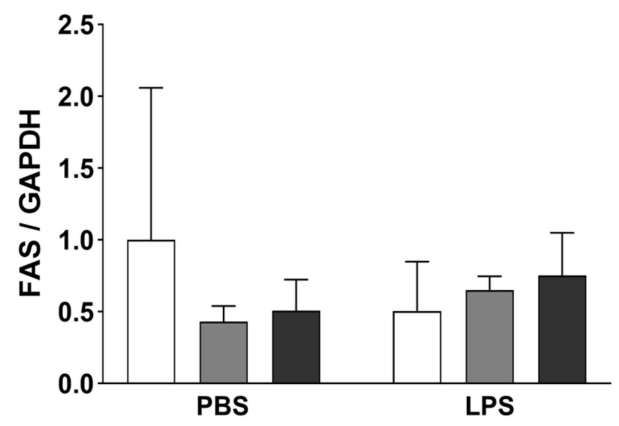

(c)

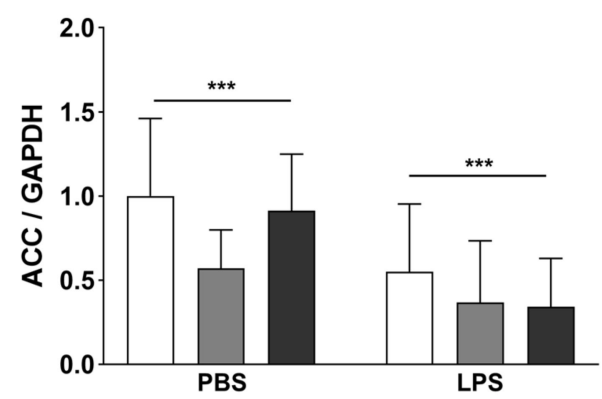

(e)

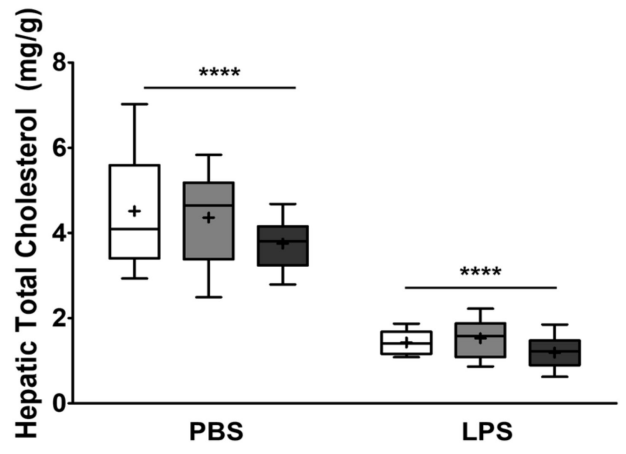

(b)

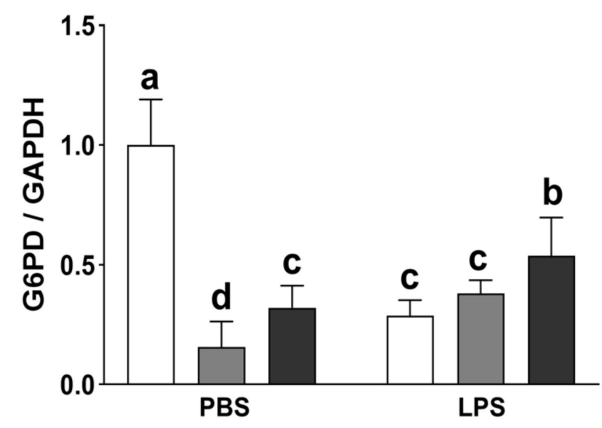

(d)

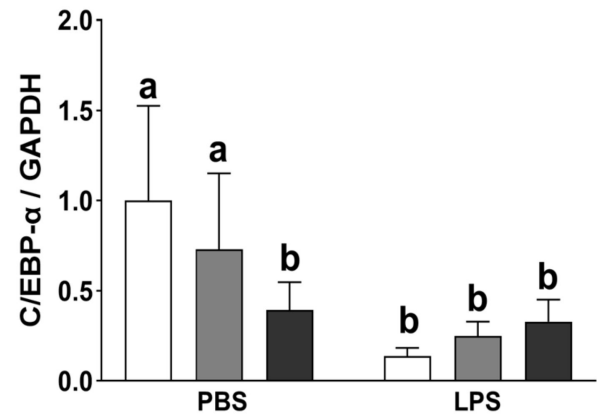

(f)

Figure 7. Cont. 


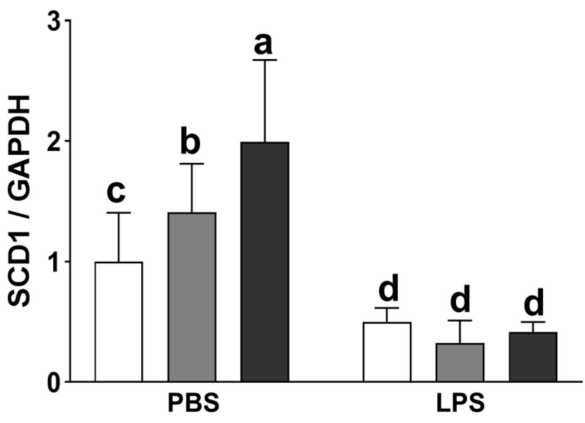

(g)

Figure 7. Effects of partial replacement of dietary fat with krill oil or coconut oil on the hepatic lipid contents and mRNA expression of lipogenesis-related genes in rats after the LPS challenge. Sprague Dawley rats were fed either a high-fat diet (HFD), HFD partially replaced with krill oil (HFD + KO), or coconut oil (HFD + CO) for 10 weeks, and then treated with PBS or LPS (1 mg/kg) for $24 \mathrm{~h}$. (a) Hepatic triglyceride content, (b) hepatic total cholesterol content, (c) fatty acid synthase (FAS), (d) glucose-6phosphate dehydrogenase (G6PD), (e) acetyl CoA carboxylase (ACC), (f) CCAAT/enhancer-binding protein alpha $(\mathrm{C} / \mathrm{EBP}-\alpha)$, and (g) stearoyl-CoA desaturase-1 (SCD1) mRNA expression levels were measured. Values are presented as means $\pm S D ; n=8$ per individual group. Data were analyzed by two-way ANOVA followed by Tukey's multiple comparisons test to determine the interactions or the main effects (diet and LPS stimulation). Asterisk indicates a significant main effect for LPS $\left.{ }^{* * *} p<0.001,{ }^{* * * *} p<0.0001\right)$. Pound indicates a significant main effect for LPS $\left({ }^{\#} p<0.05\right)$. Labeled means without a common letter differ significantly, $p<0.05$. HFD, high-fat diet; HFD + KO, highfat diet + krill oil; HFD + CO, high-fat diet + coconut oil; PBS, phosphate-buffered saline; LPS, lipopolysaccharide.

\subsection{Effect of the Dietary Fat Replacement with KO or CO on Hypertrophy and Macrophage Infiltration in Epididymal Adipose Tissue}

To demonstrate the effect of fat replacement with $\mathrm{KO}$ or $\mathrm{CO}$ and LPS challenge on hypertrophy and macrophage infiltration in EAT, we performed H\&E staining and measured fibrosis markers and expression of proinflammatory cytokines. Histological examination of EAT sections (Figure 8a) and subsequent quantification of adipocyte size confirmed very large adipocytes in rats fed with HFD $(p<0.001$, Figure $8 b)$. Notably, rats fed with HFD + KO exhibited much lower adipocyte hypertrophy than those fed with HFD (Figure 8a,b). Additionally, the adipocyte size of the HFD + CO group decreased by $40 \%$ after LPS treatment. The CLS is a histological feature found in the obese adipose tissue and has been demonstrated to be a proinflammatory macrophage surrounding adipocytes. The CLS was prominently observed in LPS-challenged rats $(p<0.01$; Figure $8 \mathrm{c})$. The number of CLS in rats showed a significant interaction between LPS and diet $(p<0.01)$, as it was highest in LPS-treated rats fed with HFD + CO, whereas there was no statistical significance in other experimental groups. These results indicated that fat replacement with $\mathrm{KO}$ or $\mathrm{CO}$ effectively improved LPS challenge-mediated fat inflammation, and $\mathrm{KO}$ responded more effectively. In both the presence and absence of LPS, TGF- $\beta 1$ expression in KO-fed rats is similar to that in the HFD group; however, the HFD + CO group had significantly higher TGF- $\beta 1$ expression than the other experimental groups $(p<0.01$, Figure $8 \mathrm{~d})$. The expression of IL-1 $\beta$ and CXCL-1 in the EAT is significantly upregulated by LPS stimulation (Figure 8e,f) by 22.98-fold and 20.59-fold, respectively, compared to the PBS group $(p<0.0001$; IL-1 $\beta$, $p<0.001$; CXCL-1). Following LPS treatment, CXCL-1 expression in the EAT of rats fed with HFD + KO or HFD + CO diet was lower than that in the HFD group. Furthermore, in the EAT of rats fed with HFD + KO with LPS treatment, IL-1 $\beta$ expression was lower than that in the HFD group. 


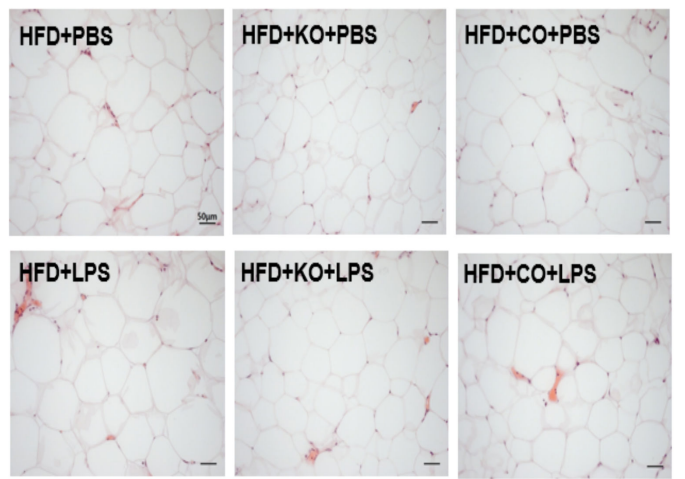

(a)

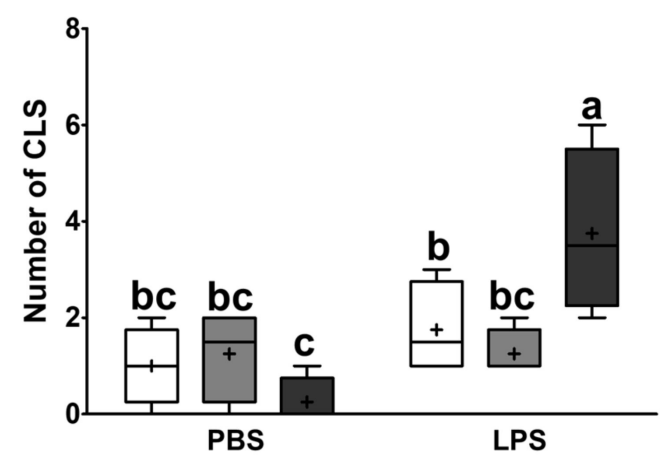

(c)

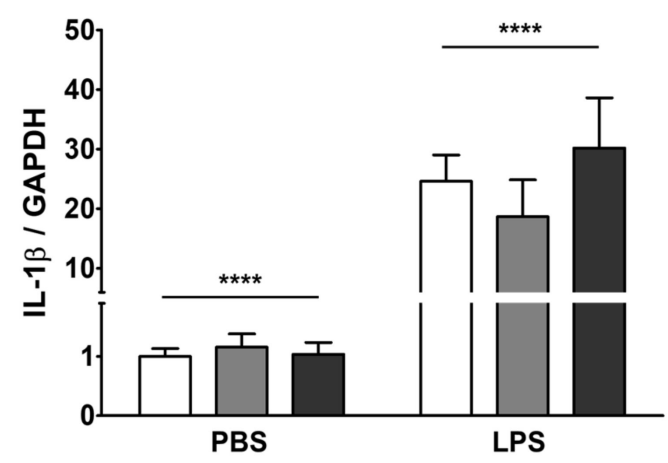

(e)

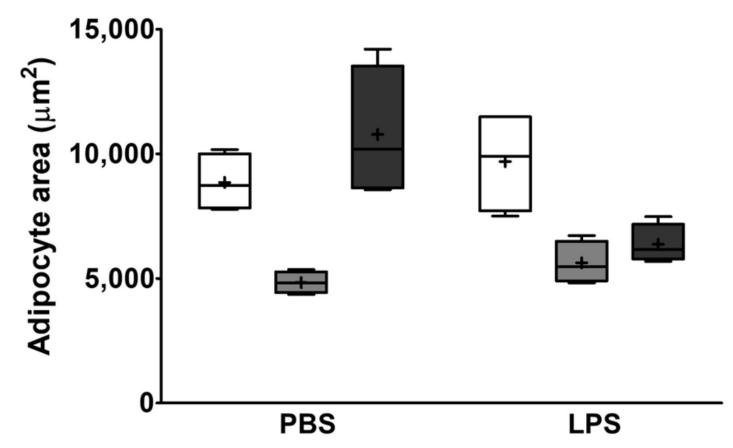

(b)

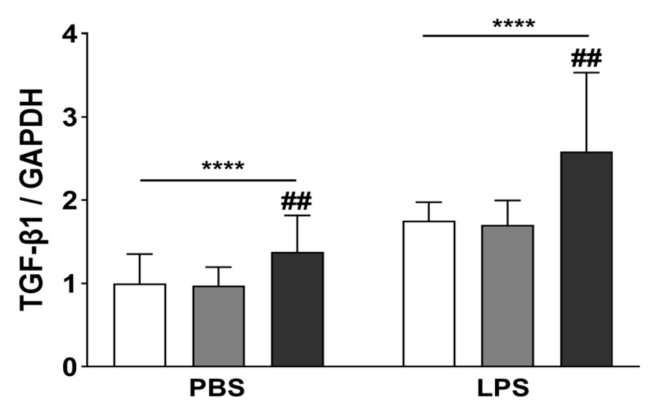

(d)

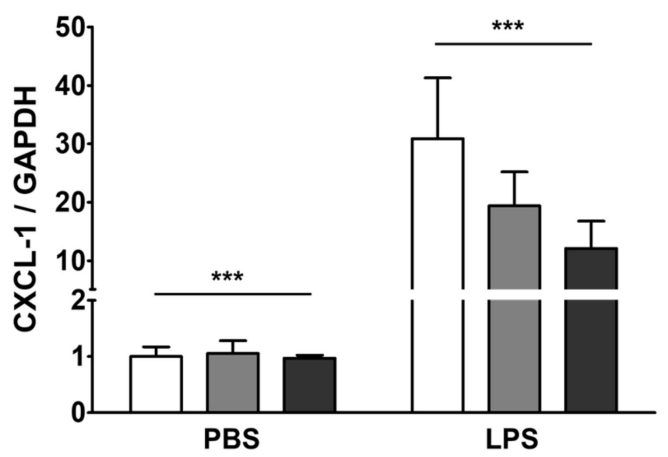

(f)

Figure 8. Effects of partial replacement of dietary fat with krill oil or coconut oil on the adipocyte histopathology and mRNA expression of proinflammatory genes in epididymal adipose tissues (EAT) of rats after the LPS challenge. Sprague Dawley rats were fed either a high-fat diet (HFD), HFD partially replaced with krill oil (HFD + KO), or coconut oil (HFD + CO) for 10 weeks, and then treated with PBS or LPS $(1 \mathrm{mg} / \mathrm{kg}$ ) for $24 \mathrm{~h}$. (a) Hematoxylin and eosin (H\&E) staining of EAT (bar $=50 \mu \mathrm{m}, 20 \times$ magnification), (b) adipocyte area from each group, (c) number of crown-like structures (CLS), (d) transforming growth factor- $\beta 1$ (TGF- $\beta 1)$, (e) interleukin 1 beta (IL-1 $\beta$ ) level, and (f) chemokine (C-X-C motif) ligand 1 (CXCL-1) levels were measured. Values are displayed as box-and-whisker plots, $\mathrm{n}=8$ for individual group. Data were analyzed by two-way ANOVA followed by Tukey's multiple comparisons test to determine the interactions or the main effects (diet and LPS stimulation). Asterisk indicates a significant main effect for LPS $(* * *<0.001, * * * * p 0.0001)$. Pound indicates a significant main effect for diet $\left({ }^{\#} p<0.01\right)$. Labeled means without a common letter differ significantly, $p<0.05$. The mean values are indicated by " + " signs. HFD, high-fat diet; HFD + KO, high-fat diet + krill oil; HFD + CO, high-fat diet + coconut oil; PBS, phosphate-buffered saline; LPS, lipopolysaccharide. 


\section{Discussion}

High dietary fat induces overconsumption, hepatic fat accumulation, and increased BW gain, which can further lead to obesity [57]. It has been widely demonstrated that obesity leads to a number of health complications, including diabetes, heart disease, hypertension, chronic kidney disease, and cancers [58]. The total dietary fat intake has been previously believed to be a main predictor of obesity, as fat is the most energy-dense macronutrient; however, the current focus has shifted to the quality or types of dietary fat [59]. It is well-established that a high intake of SFAs induces local inflammation and adverse cardiometabolic effects [60,61]. However, the administration of PUFAs has been reported to exert various health benefits, including potent mediators of adiposity, dietinduced inflammation, dyslipidemia, and insulin resistance in rats $[62,63]$. Furthermore, MCFAs have been shown to be associated with anti-inflammatory activities [64] and cardioprotective effects by raising high-density lipoproteins [65] and reducing blood pressure and heart rate [66]. Therefore, replacing SFAs with alternative ingredients to prevent obesity-related metabolic disturbances and its related risks for CVD has gained substantial attention $[67,68]$. Recent studies suggest that diet-induced obesity (DIO) in rats alters cytokine production and impairs liver function and morphology in response to acute inflammatory stimuli such as LPS. Despite their beneficial pharmacological activities, antiinflammatory and cardioprotective effects of MCFAs and PUFAs in rats in response to LPS remain to be elucidated. Our investigation was designed to understand the effects of partial replacement of dietary fat with different fatty acids ( $n-3$ PUFAs or MUFAs) without energy reduction from fat. We thus utilized a rat model of HFD-induced obesity to assess the impact of different fatty acids on lipid metabolism when challenged with LPS.

The HFD, often referred to as the "Western diet" contains approximately $45 \%$ of energy from fat, 36\% from carbohydrates, and 19\% from protein, whereas a standard chow diet is composed of $18 \%, 58 \%$, and $24 \%$ of calories from fat, carbohydrates, and protein, respectively [69]. In this study, the HFD created for this study was composed of various amounts of Western blend ( $~ 83 \%$ of energy from milk fat) for the replacement of dietary fat with $\mathrm{KO}$ or CO. [70]. Dietary fat compositions can alter metabolic function and influence BW, composition, and whole-body energetics [71]. As summarized in Table 6, the potential of $\mathrm{KO}$ against obesity in experimental rats has been investigated in many studies. In C57BL/ 6 mice fed with a HFD, Tandy et al. [34] investigated the dose-dependent effects of dietary $\mathrm{KO}$ supplementation on cardiovascular and metabolic parameters and suggested that supplementation with a high dose of $\mathrm{KO}(2.5 \%$ or $5.0 \%)$ was a more beneficial effect than a low dose of KO (1.25 wt.\%). Furthermore, Sun et al. [33] demonstrated that dyslipidemia, fatty liver, and glucose metabolism were improved in C57BL/6 J mice fed with HFD and with $5.0 \%$ substituent of KO for 12 weeks. Other studies that fed a HFD confirmed that supplementation with $2.0-2.5 \%(w / w)$ of $\mathrm{KO}$ had an anti-obesity effect. Famurewa et al. [72] and Hima et al. [73] reported that supplementation of $4 \sim 16 \%$ coconut oil in the diet improved oxidative stress, inflammation, and apoptosis via improvement in antioxidant mechanism by increasing antioxidative enzymatic activities and inflammatory signaling pathways as a post-translational manner (Table 7). 
Table 6. Effects of krill oil in animal models with metabolic disease.

\begin{tabular}{|c|c|c|c|c|}
\hline Strain & Inducer & Treatment & Biological Markers & Ref. \\
\hline C57BL/6J mouse & HFD & $5 \%(w / w)$ for 12 weeks & $\begin{array}{c}\text { Liver and epididymal fat weights } \downarrow \\
\text { Serum TC, LDL-C levels } \downarrow \\
\text { Serum and liver MDA level, ALT activity } \downarrow \\
\text { Serum and liver SOD levels } \uparrow\end{array}$ & {$[33]$} \\
\hline C57BL/6N mouse & HFD & $2 \%(w / w)$ for 12 weeks & $\begin{array}{c}\text { Body weight and abdominal fat } \\
\text { (visceral and subcutaneous) contents } \downarrow \\
\text { Hepatic weight and hepatic steatosis } \downarrow \\
\text { Serum TG, LDL-C levels } \downarrow \\
\text { Fatty acid synthesis related genes expression } \downarrow\end{array}$ & {$[22]$} \\
\hline $\begin{array}{l}\text { Sprague-Dawley } \\
\text { rats }\end{array}$ & HFD & $\begin{array}{c}2.5 \%(w / w) \text { for } \\
12 \text { weeks }\end{array}$ & $\begin{array}{c}\text { Body weight gain } \downarrow \\
\text { Hepatic fatty acid oxidation related gene } \\
\text { expression } \uparrow \\
\text { Plasma TG levels } \downarrow \\
\text { Hepatic TG, TC levels } \downarrow \\
\text { Glucose and insulin concentration } \downarrow\end{array}$ & {$[28]$} \\
\hline
\end{tabular}

Liver weight $\downarrow$

Hepatic TG, TC levels $\downarrow$

Serum TC, glucose $\downarrow$

Serum adiponectin $\uparrow$

Hepatic TNF- $\alpha$ level and mRNA expression $\downarrow$

Hepatic FA synthesis associated with gene expression

(FAS, ACC, SCD-1) $\downarrow$

C57BL/6 mouse $\quad$ HFD $1.25,2.5$, and $5 \%(w / w)$
for 8 weeks

Hepatic FA catabolism associated with gene expression (MGLL, LIPE) $\downarrow$

Hepatic FA oxidation associated with gene expression (CPT-1) $\downarrow$

Hepatic cholesterol metabolism associated with gene expression (HMG CoA-R, LDL-R) $\downarrow$

Hepatic transcription factors gene expression

(SREBP-1c, SREBP-2, PPAR- $\alpha) \downarrow$

$\uparrow$, increased; $\downarrow$, decreased; HFD, high-fat diet; ACC, acetyl-CoA carboxylase; ALT, alanine transaminase; CPT-1, carnitine palmitoyl transferase I; FA, fatty acid; FAS, fatty acid synthesis; HMG-CoA; 3-hydroxy-3-methylglutaryl coenzyme A reductase; LDL-C, low-density lipoprotein-cholesterol; LDL-R, low-density lipoprotein receptor; LIPE, hormone-sensitive lipase; MDA, malondialdehyde; MGLL, monoglyceride lipase; PPAR- $\alpha$, peroxisome proliferator-activated receptor- $\alpha$; SCD-1, stearoyl-CoA desaturase-1; SOD, sodium oxide dismutase; SREBP, sterol regulatory element binding protein; TC, total cholesterol; TG, triglyceride; TNF- $\alpha$, tumor necrosis factor- $\alpha$.

Table 7. Effects of coconut oil in animal models with metabolic disease.

\begin{tabular}{|c|c|c|c|c|}
\hline Strain & Inducer & Treatment & Biological Markers & Ref. \\
\hline Wistar rats & $\begin{array}{l}\text { Paracetamol, } \\
750 \text { mg/kg body } \\
\text { weight (i.p.) }\end{array}$ & $\begin{array}{c}\text { Virgin coconut oil } \\
\text { (phoscoliv) } \\
0.5 \mathrm{~mL} / 100 \mathrm{~g} \text { body weight }\end{array}$ & $\begin{array}{c}\text { Serum proinflammatory cytokines } \\
\text { (IL-6, TNF- } \alpha \text { ) } \downarrow \\
\text { Histological scoring of liver } \\
\text { tissue } \downarrow\end{array}$ & [74] \\
\hline Wistar rats & $\begin{array}{l}\text { HFD ( } 60 \% \text { of calories } \\
\text { from fat) }\end{array}$ & $\begin{array}{l}\text { high-coconut oil diet }(60 \% \\
\text { of calories from coconut } \\
\text { oil) for } 3 \text { days }\end{array}$ & $\begin{array}{l}\text { Serum glucose, insulin, leptin } \\
\text { concentrations } \downarrow \\
\text { Protein levels of inflammatory } \\
\text { markers in the hippocampi } \\
\text { and prefrontal cortices (IL-1 } \beta \text {, IL-6, } \\
\text { TNF- } \alpha \text { and NF-kB) } \downarrow\end{array}$ & [75] \\
\hline
\end{tabular}


Table 7. Cont.

\begin{tabular}{|c|c|c|c|c|}
\hline Strain & Inducer & Treatment & Biological Markers & Ref. \\
\hline Sprague-Dawley rats & $\begin{array}{c}\text { LPS } 10 \text { mg/kg body } \\
\text { weight (i.p.) }\end{array}$ & $\begin{array}{l}\text { Lauric acid } 50,100 \mathrm{mg} / \mathrm{kg} \\
\text { body } \\
\text { weight (p.o.) for } 14 \text { days }\end{array}$ & $\begin{array}{c}\text { Serum AST, ALT levels } \downarrow \\
\text { Serum TC, non-HDL-C, LDL-C } \\
\text { and TG } \downarrow \\
\text { Serum HDL-C } \uparrow \\
\text { Serum proinflammatory cytokines } \\
\text { (TNF- } \alpha, \text { IL-6, IL-1 } \beta \text { ) } \downarrow \\
\text { Hepatic proinflammatory } \\
\text { cytokines } \\
\text { (TNF- } \alpha, \text { IL-6, IL-1 } \beta \text { ) } \downarrow \\
\text { Hepatic protein expression of } \\
\text { TLR4, MyD88, NF- } \mathrm{B}, \text { TNF- } \alpha, \\
\text { IL-1 } \beta \downarrow\end{array}$ & [76] \\
\hline C57BL/6 mouse & HFD & $\begin{array}{c}1.25,2.5, \text { and } 5 \%(w / w) \text { for } \\
8 \text { weeks }\end{array}$ & $\begin{array}{c}\text { Liver weight } \downarrow \\
\text { Hepatic TG, TC levels } \downarrow \\
\text { Serum TC, glucose } \downarrow \\
\text { Serum adiponectin } \uparrow \\
\text { Hepatic TNF- } \alpha \text { level, mRNA } \\
\text { expression } \downarrow \\
\text { Hepatic FA synthesis associated } \\
\text { with gene expression } \\
\text { (FAS, ACC, SCD-1) } \downarrow\end{array}$ & {$[77]$} \\
\hline
\end{tabular}

Renal oxidative stress index

(SOD, CAT, GPx, GSH, MDA) $\downarrow$

Renal inflammatory cytokines

Wistar rats

\section{Gentamicin, $100 \mathrm{mg} / \mathrm{kg}$} body weight (i.p.)

\section{Virgin coconut oil 10\%} $(w / w)$ for 16 days
(IL- $1 \beta$, IL-6, TNF- $\alpha$, NO, iNOS) $\downarrow$ Renal NF- $k$ B level $\downarrow$

Renal caspase-3 activity $\downarrow$

Renal histomorphology $\downarrow$

\section{Proinflammatory cytokine (TNF- $\alpha$ ) production in the splenocytes $\downarrow$ p-mTOR, SIRT1, and p-LKB1 expression in the spleen $\uparrow$ p-ERK1/2/Total ERK1/2, p-CREB/Total CREB expression in the spleen $\uparrow$ Splenic SOD and CAT activities $\uparrow$ Serum HDL-C level $\uparrow$}

Virgin coconut oil 4, 8, 16\% $(w / w)$ for 30 days

$\uparrow$, increased; $\downarrow$, decreased; HFD, high-fat diet; ACC, acetyl-CoA carboxylase; ALT, alanine aminotransferase AST, aspartate transaminase; CAT, catalase; CREB, cAMP response element-binding protein; ERK, extracellularsignal-regulated kinase; FA, fatty acid; FAS, fatty acid synthase; GPx, glutathione peroxidase; GSH, glutathione; IL-1 $\beta$, interleukin-1 $\beta$; IL-6, interleukin 6; iNOS, inducible nitric oxide synthase; LDL-C, low-density lipoproteincholesterol; MDA, malondialdehyde; mTOR, mammalian target of rapamycin; MYD88, myeloid differentiation primary response 88 ; NF- $\mathrm{kB}$, nuclear factor kappa-light-chain-enhancer of activated $\mathrm{B}$ cells; non-HDL-C, non-highdensity lipoprotein cholesterol; NO, nitric oxide; SCD-1, stearoyl-CoA desaturase; SOD, sodium oxide dismutase; SIRT1, sirtuin 1; LKB1, liver kinase B1; TC, total cholesterol; TG, triglyceride; TNF- $\alpha$, tumor necrosis factor- $\alpha$; TLR4, toll-like receptor 4 .

Many studies have reported the weight-lowering effects of MCFAs $[76,79,80]$ or PUFAs $[28,81]$. However, in the present study, although rats fed with HFD + KO and HFD + CO showed slightly, but significantly, lower daily food intake, we did not observe differences in BW and FER among the different groups in our experimental settings. Thus, it is likely that one cause of the discrepancies might be attributed to the insufficient quantity of the $\mathrm{KO}$ or $\mathrm{CO}$ to exhibit pronounced BW loss.

Obesity is a leading risk factor for T2D and metabolic syndrome. Chronic overfeeding triggers inflammation and further leads to peripheral insulin resistance and hyperinsulinemia $[49,82]$. Based on our findings from OGTT and ITT, HFD + KO and HFD + CO did not 
alter glucose metabolism. The average serum glucose in male SD rats at 17 weeks of age or older ranges from 106 to $184 \mathrm{mg} / \mathrm{dL}$ [83]. This indicates that HFD markedly elevated fasting glucose levels along with serum insulin, whereas HFD + KO and HFD + CO reduced serum glucose levels close to normal levels in the absence of LPS. These results indicate that both HFD + KO and HFD + CO promoted a reduction in HOMA-IR levels. HOMA-IR is a well-established method for estimating beta cell function and insulin resistance at a steady state, in which high HOMA-IR values indicate low insulin sensitivity, such as insulin resistance $[84,85]$. Consistent with our findings, previous studies on $n-3$ PUFAs have demonstrated its protective effects against insulin resistance [28,86]. In the present study, CO consumption in rats (without LPS administration) reduced serum glucose and insulin levels, as well as HOMA-IR values. However, the effects of MCFAs on glucose metabolism remain contradictory, with some studies observing the ameliorating effects of MCFAs on insulin resistance $[87,88]$, whereas others do not $[75,77]$. Thus, further research is needed to understand the mechanisms underlying the effects of MCFAs on insulin sensitivity. Moreover, the findings of the current study indicate that LPS injection increased serum glucose and insulin levels. This is consistent with previous studies suggesting that LPS might be involved in glucose-induced hyperinsulinemia, possibly via activation of toll-like receptor 4 (TLR4) [89].

Atherogenic dyslipidemia is characterized by elevated levels of TG, TC, and LDL-C, along with reduced levels of HDL-C [90]. Studies have reported that LPS injection induces hyperlipidemia by significantly increasing total lipids, TC, TG, AST, and ALT activities [91-93]. A study by Khan et al. [76] showed elevation in serum TC, non-HDL-C, LDL-C, and TG of LPS-treated male SD rats. Our findings were in accordance with previous studies showing that administration of LPS promoted hyperlipidemia, accompanied by elevated TG, TC, HDL-C, non-HDL-C, and CVD expectancy markers (i.e., AC and CRF) [93,94]. Our results highlighted in Figure 3 indicate that $\mathrm{KO}$ and $\mathrm{CO}$ consumption attenuated these significantly elevated levels. These results were consistent with the report by Sun et al. that KO feeding lowered serum TC and LDL-C levels in HFD-induced dyslipidemia mice [33]. In accordance with this, several studies have reported the preventive effects of $\mathrm{CO}$ against dyslipidemia, associated with reduced TC, TG, phospholipids, LDL-C, and VLDL-C [95,96]. Consequently, these studies suggest that $\mathrm{KO}$ and $\mathrm{CO}$ supplementation exhibit beneficial effects, particularly on lipid metabolism and CVD expectancy. Furthermore, the AST and ALT levels are indicators of dyslipidemia and liver injury [97]. As presented in the present study, the administration of LPS induced elevated levels of serum AST and ALP activities, indicating liver damage. In accordance with our results, other studies have reported a reduction in the serum AST and ALT levels due to MCFAs [98] and PUFAs [99]. PUFAs consumption may prevent NAFLD by attenuation of ectopic fat accumulation in the liver $[100,101]$. Less ectopic fat accumulation could decrease hepatic damage per 2-hit hypothesis by reducing inflammation and oxidative stress [102].

Adipose tissue accumulation in obesity increases the number of macrophages and promotes local and systemic inflammation [103]. As visceral obesity is an important risk factor for developing metabolic syndrome and CVD, we assessed the weights of several visceral fat depositions, including EAT, MAT, RAT, and PAT. Our findings in Figure 2 suggest that neither $\mathrm{KO}$ nor $\mathrm{CO}$-replaced diets showed significant effects on the weights in the liver and various fat depots. The rats fed with HFD + KO exhibited a decreasing trend in the weights of different adipose depots, in which WAT and RAT showed a diet main effect. These findings were further explored in EAT, a metabolically active tissue widely used to study lipid metabolism in rodents [104]. WAT expansion involves two distinct processes: hyperplasia and hypertrophy; however, visceral WAT expansion mainly occurs due to hypertrophy [105]. Evidence suggests that adipocyte hypertrophy is associated with increased inflammation $[106,107]$. WAT dysfunction is characterized by adipocyte hypertrophy, macrophage infiltration, the appearance of CLS, and elevated expression of inflammatory genes $[105,108]$. In accordance with the weights of various fat pads (Figure $2 \mathrm{~b}-\mathrm{f}$ ), KO consumption in rats alleviated the development of hypertrophic EAT. 
However, in the present study, HFD + KO did not noticeably influence the number of CLS, implying that the $\mathrm{KO}$ quantity was insufficient to alter macrophage infiltration caused by HFD. These results are consistent with those of previous studies using HFD supplemented with KO [109] or fish oil [110]. Conversely, previous studies also reported adipocyte hypertrophy associated with CO, which is also indicated in our study [111,112]. HFDinduced obesity results in chronic low-grade inflammation. Thus, the effects of $\mathrm{KO}$ and $\mathrm{CO}$ on the cytokines and chemokines, such as IL-1 $\beta$, MCP-1, and CXCL-1, are further assessed in the serum (Figure 5a,b), liver (Figure 6d,e), and EAT (Figure 8e,f). However, no prominent differences were noted among the different diets. Moreover, LPS exposure from Gram-negative bacterial infections induces the excessive release of proinflammatory cytokines [113-115]. Mechanistically, LPS binds to LPS binding protein in the blood and recruits CD14 to form a complex. After ligand binding, the complex is translocated to the TLR4 receptor complex for dimerization. The conformational change then initiates the subsequent activation of downstream inflammatory signaling through the activation of NF-KB and MAPK signaling pathways $[89,98,116,117]$. In the present study, after LPS treatment, the HFD + KO and HFD + CO groups showed downregulated mRNA expression of proinflammatory cytokines in the liver (CXCL-1) and EAT, such as IL-1 $\beta$ and CXCL-1, as compared to the HFD group. In summary, our findings on proinflammatory cytokine and chemokine levels in the serum, liver, and EAT indicate that $\mathrm{KO}$ and $\mathrm{CO}$ contents were not able to prominently downregulate the stimulation of TLR4 signaling pathway, possibly due to insufficient $\mathrm{KO}$ and $\mathrm{CO}$ levels.

Obesity is associated with various metabolic disorders, and NAFLD is one such condition. NAFLD is a chronic liver disease that ranges from benign steatosis to nonalcoholic steatohepatitis (NASH) [118]. NASH is caused by fat accumulation in the hepatocytes and may progress to fibrosis, cirrhosis, liver failure, or hepatocellular carcinoma [119]. In addition to obesity, bacterial endotoxins such as LPS are key factors in the pathogenesis of NASH [120]. The underlying mechanism of NAFLD pathogenesis is widely accepted as the "two-hit hypothesis" [121]. The onset of disease starts with the first hit involving hepatic TG accumulation and insulin resistance, followed by the second hit, resulting in more severe liver injury associated with impaired inflammatory cytokines, adipokines, mitochondrial dysfunction, and oxidative stress [121,122]. Thus, we analyzed common parameters used for the diagnosis of NAFLD to observe the hepatoprotective effects of MCFAs and PUFAs. A previous study reported that PUFAs mediate hepatic enzymes involved in anabolic pathways, including ACC and FAS; thus, promoting a decrease in hepatic adiposity [123]. In this study, although the weight of the liver was not significantly changed, hepatic TGs and lipogenesis-related genes (FAS, G6PD, and ACC) showed a decreasing pattern followed by KO consumption in the absence of LPS. A similar pattern was observed in hepatic histology and fibrosis markers according to KO supplementation. However, among the various steatosis-related parameters, CO supplementation only showed a slight improvement in G6PD compared to HFD. Our findings were consistent with previous results reported by Ferramosca et al., where supplementation of KO in the HFD prevented TG accumulation in the liver as well as de novo fatty acid synthesis in the liver [28]. These protective effects of $\mathrm{KO}$ against liver injury might be related to the inactivation of NF- $\mathrm{kB} / \mathrm{MAPK}$ signaling pathways, as discussed above. LPS causes anabolic lipid accumulation in the liver; however, based on our study, LPS administration decreased lipid accumulation in the liver. These results might be because LPS induces strong autophagy in the liver and hepatocytes. Studies have reported that LPS-treated mice showed reduced hepatic lipid accumulation with higher induction of autophagy compared to controls [124]. However, chloroquine treatment inhibited LPS-induced autophagy and increased lipid accumulation in the liver. In this study, hepatic lipid accumulation increased in the $\mathrm{CO}$ diet in LPS-treated rats. Furthermore, the expression of adipogenesis transcription factors and adipogenic enzymes increased slightly in $\mathrm{KO}$ - and $\mathrm{CO}$-fed rats. This indicates that an increase in endotoxin-induced autophagy may modulate lipid metabolism changes, and further studies are needed to identify the underlying mechanisms. These findings indicate 
that partial replacement of HFD with $\mathrm{KO}$ might be partly associated with the prevention of liver steatosis and fibrosis.

\section{Conclusions}

Diet-induced obesity leads to various adverse health complications, such as hyperglycemia, dyslipidemia, and hypertension, and further increases the risk of CVD. Taken together, we have shown that partial replacement of HFD with KO or CO improved DIOinduced adiposity, glucose homeostasis, insulin resistance, serum lipid profiles, and hepatic steatosis. More pronounced results were observed in the rats that consumed KO. The protective effects of $\mathrm{KO}$ against liver injury might be associated with the inactivation of NF- $\mathrm{B}$ /MAPK signaling pathways. These results suggest that $n-3$ PUFAs or MCFAs supplementation may be utilized as a replacement source of a HFD to ameliorate the metabolic dysregulation caused by obesity. However, long-term studies are needed to thoroughly understand the mechanisms underlying the utilization of $n-3$ PUFAs or MCFAs supplementation in clinical trials.

Author Contributions: Conceptualization, H.-K.S. and J.-H.H.; methodology, H.-K.S., J.L., S.P., C.-B.O., S.J. and J.-H.H.; software, H.-K.S., B.-H.K., J.L., S.P., C.-B.O., S.J., J.K.L. and J.-H.H.; validation, H.-K.S., J.K.L. and J.-H.H.; formal analysis, H.-K.S., J.L., S.P., C.-B.O., S.J., J.K.L. and J.-H.H.; investigation, H.-K.S., S.J., J.K.L. and J.-H.H.; resources, B.-H.K. and J.-H.H.; data curation, H.-K.S. and J.K.L.; writing-original draft preparation, H.-K.S., B.-H.K., J.L., S.P., C.-B.O., S.J., J.K.L. and J.-H.H.; writing—review and editing, H.-K.S., B.-H.K., J.K.L. and J.-H.H.; visualization, H.-K.S., J.L., S.P., S.J. and J.K.L.; supervision, H.-K.S., B.-H.K., J.L., S.P., C.-B.O., S.J., J.K.L. and J.-H.H.; project administration, J.-H.H.; funding acquisition, J.-H.H. All authors have read and agreed to the published version of the manuscript.

Funding: This research was supported by Korea Institute of Planning and Evaluation for Technology in Food, Agriculture and Forestry (IPET) through Innovative Food Product and Natural Food Materials Development Program, funded by Ministry of Agriculture, Food and Rural Affairs (MAFRA) (319045-3).

Institutional Review Board Statement: The animal study protocol was approved by the Dankook University Institutional Animal Care and Use Committee (IACUC, No. DKU-21-051 approved on 14 September 2021).

Informed Consent Statement: This study was approved by the Institutional Animal Care and Use Committee of Dankook University (protocol code DKU-21-051).

Data Availability Statement: The data presented in this study are available from the corresponding authors upon request.

Conflicts of Interest: The authors declare no conflict of interest.

\section{References}

1. Kelly, T.; Yang, W.; Chen, C.-S.; Reynolds, K.; He, J. Global burden of obesity in 2005 and projections to 2030. Int. J. Obes. 2008, 32, 1431-1437. [CrossRef] [PubMed]

2. World Health Organization. Obesity and Overweight. Available online: https://www.who.int/news-room/fact-sheets/detail/ obesity-and-overweight (accessed on 6 January 2022).

3. Center for Disease Control and Prevention. Prevalence of Obesity and Severe Obesity Among Adults: United States, 2017-2018. Available online: https:/ / www.cdc.gov/nchs/products/databriefs/db360.htm (accessed on 6 January 2022).

4. Collaboration, N.R.F. Trends in adult body-mass index in 200 countries from 1975 to 2014: A pooled analysis of 1698 populationbased measurement studies with 19.2 million participants. Lancet 2016, 387, 1377-1396. [CrossRef]

5. Muscogiuri, G.; Barrea, L.; Savastano, S.; Colao, A. Nutritional recommendations for CoVID-19 quarantine. Eur. J. Clin. Nutr. 2020, 74, 850-851. [CrossRef] [PubMed]

6. Aghili, S.M.M.; Ebrahimpur, M.; Arjmand, B.; Shadman, Z.; Sani, M.P.; Qorbani, M.; Larijani, B.; Payab, M. Obesity in COVID-19 era, implications for mechanisms, comorbidities, and prognosis: A review and meta-analysis. Int. J. Obes. 2021, 45, 998-1016. [CrossRef]

7. Shin, S.; Ajuwon, K.M. Lipopolysaccharide Alters Thermogenic and Inflammatory Genes in White Adipose Tissue in Mice Fed Diets with Distinct 18-Carbon Fatty-Acid Composition. Lipids 2018, 53, 885-896. [CrossRef] 
8. Camp, H.S.; Ren, D.; Leff, T. Adipogenesis and fat-cell function in obesity and diabetes. Trends Mol. Med. 2002, 8, 442-447. [CrossRef]

9. Sun, J.; Zhou, W.; Gu, T.; Zhu, D.; Bi, Y. A retrospective study on association between obesity and cardiovascular risk diseases with aging in Chinese adults. Sci. Rep. 2018, 8, 5806. [CrossRef]

10. Estruch, R.; Ros, E.; Salas-Salvadó, J.; Covas, M.-I.; Corella, D.; Arós, F.; Gómez-Gracia, E.; Ruiz-Gutiérrez, V.; Fiol, M.; Lapetra, J. Primary prevention of cardiovascular disease with a Mediterranean diet. N. Engl. J. Med. 2013, 368, 1279-1290. [CrossRef]

11. Masoodi, M.; Kuda, O.; Rossmeisl, M.; Flachs, P.; Kopecky, J. Lipid signaling in adipose tissue: Connecting inflammation \& metabolism. Biochim. Biophys. Acta (BBA)-Mol. Cell Biol. Lipids 2015, 1851, 503-518. [CrossRef]

12. Evert, A.B.; Boucher, J.L.; Cypress, M.; Dunbar, S.A.; Franz, M.J.; Mayer-Davis, E.J.; Neumiller, J.J.; Nwankwo, R.; Verdi, C.L.; Urbanski, P. Nutrition therapy recommendations for the management of adults with diabetes. Diabetes Care 2014, 37, S120-S143. [CrossRef]

13. Liu, A.G.; Ford, N.A.; Hu, F.B.; Zelman, K.M.; Mozaffarian, D.; Kris-Etherton, P.M. A healthy approach to dietary fats: Understanding the science and taking action to reduce consumer confusion. Nutr. J. 2017, 16, 53. [CrossRef]

14. White, B. Dietary fatty acids. Am. Fam. Physician 2009, 80, 345-350.

15. World Health Organization. Healthy Diet. Available online: https://www.who.int/publications/m/item/healthy-diet-factsheet3 94 (accessed on 6 January 2022).

16. World Health Organization. Diet, Nutrition, and the Prevention of Chronic Diseases: Report of a Joint WHO/FAO Expert Consultation; World Health Organization: Geneva, Switzerland, 2003; Volume 916.

17. Ulven, S.M.; Holven, K.B. Comparison of bioavailability of krill oil versus fish oil and health effect. Vasc. Health Risk Manag. 2015, 11, 511. [CrossRef]

18. Kwantes, J.M.; Grundmann, O. A brief review of krill oil history, research, and the commercial market. J. Diet. Suppl. 2015, 12, 23-35. [CrossRef]

19. Burri, L.; Hoem, N.; Banni, S.; Berge, K. Marine omega-3 phospholipids: Metabolism and biological activities. Int. J. Mol. Sci. 2012, 13, 15401-15419. [CrossRef]

20. Salem, N.; Kuratko, C.N. A reexamination of krill oil bioavailability studies. Lipids Health Dis. 2014, 13, 137. [CrossRef]

21. Gigliotti, J.C.; Davenport, M.P.; Beamer, S.K.; Tou, J.C.; Jaczynski, J. Extraction and characterisation of lipids from Antarctic krill (Euphausia superba). Food Chem. 2011, 125, 1028-1036. [CrossRef]

22. Yang, G.; Lee, J.; Lee, S.; Kwak, D.; Choe, W.; Kang, I.; Kim, S.S.; Ha, J. Krill oil supplementation improves dyslipidemia and lowers body weight in mice fed a high-fat diet through activation of AMP-activated protein kinase. J. Med. Food 2016, 19, 1120-1129. [CrossRef]

23. Kim, H.-D.; Lee, S.-B.; Ko, S.-C.; Jung, W.-K.; Kim, Y.-M.; Kim, S.-B. Anti-inflammatory effect of ozonated krill (Euphausia superba) oil in lipopolysaccharide-stimulated RAW 264.7 macrophages. Fish. Aquat. Sci. 2018, 21, 15. [CrossRef]

24. Kim, J.H.; Meng, H.W.; He, M.T.; Choi, J.M.; Lee, D.; Cho, E.J. Krill Oil Attenuates Cognitive Impairment by the Regulation of Oxidative Stress and Neuronal Apoptosis in an Amyloid $\beta$-Induced Alzheimer's Disease Mouse Model. Molecules 2020, $25,3942$. [CrossRef]

25. Ierna, M.; Kerr, A.; Scales, H.; Berge, K.; Griinari, M. Supplementation of diet with krill oil protects against experimental rheumatoid arthritis. BMC Musculoskelet. Disord. 2010, 11, 136. [CrossRef]

26. Cheong, L.-Z.; Sun, T.; Li, Y.; Zhou, J.; Lu, C.; Li, Y.; Huang, Z.; Su, X. Dietary krill oil enhances neurocognitive functions and modulates proteomic changes in brain tissues of d-galactose induced aging mice. Food Funct. 2017, 8, 2038-2045. [CrossRef]

27. Cui, C.; Li, Y.; Gao, H.; Zhang, H.; Han, J.; Zhang, D.; Li, Y.; Zhou, J.; Lu, C.; Su, X. Modulation of the gut microbiota by the mixture of fish oil and krill oil in high-fat diet-induced obesity mice. PLoS ONE 2017, 12, e0186216. [CrossRef]

28. Ferramosca, A.; Conte, A.; Burri, L.; Berge, K.; De Nuccio, F.; Giudetti, A.M.; Zara, V. A krill oil supplemented diet suppresses hepatic steatosis in high-fat fed rats. PLoS ONE 2012, 7, e38797. [CrossRef]

29. Köhler, A.; Sarkkinen, E.; Tapola, N.; Niskanen, T.; Bruheim, I. Bioavailability of fatty acids from krill oil, krill meal and fish oil in healthy subjects-a randomized, single-dose, cross-over trial. Lipids Health Dis. 2015, 14, 19. [CrossRef]

30. Kroupova, P.; van Schothorst, E.M.; Keijer, J.; Bunschoten, A.; Vodicka, M.; Irodenko, I.; Oseeva, M.; Zacek, P.; Kopecky, J.; Rossmeisl, M. Omega-3 phospholipids from krill oil enhance intestinal fatty acid oxidation more effectively than omega-3 triacylglycerols in high-fat diet-fed obese mice. Nutrients 2020, 12, 2037. [CrossRef]

31. Rundblad, A.; Holven, K.B.; Bruheim, I.; Myhrstad, M.C.; Ulven, S.M. Effects of krill oil and lean and fatty fish on cardiovascular risk markers: A randomised controlled trial. J. Nutr. Sci. 2018, 7, e3. [CrossRef]

32. Sistilli, G.; Kalendova, V.; Cajka, T.; Irodenko, I.; Bardova, K.; Oseeva, M.; Zacek, P.; Kroupova, P.; Horakova, O.; Lackner, K. Krill oil supplementation reduces exacerbated hepatic steatosis induced by thermoneutral housing in mice with diet-induced obesity. Nutrients 2021, 13, 437. [CrossRef]

33. Sun, D.; Zhang, L.; Chen, H.; Feng, R.; Cao, P.; Liu, Y. Effects of Antarctic krill oil on lipid and glucose metabolism in C57BL/6J mice fed with high fat diet. Lipids Health Dis. 2017, 16, 218. [CrossRef]

34. Tandy, S.; Chung, R.W.; Wat, E.; Kamili, A.; Berge, K.; Griinari, M.; Cohn, J.S. Dietary krill oil supplementation reduces hepatic steatosis, glycemia, and hypercholesterolemia in high-fat-fed mice. J. Agric. Food Chem. 2009, 57, 9339-9345. [CrossRef]

35. Basson, A.R.; Chen, C.; Sagl, F.; Trotter, A.; Bederman, I.; Gomez-Nguyen, A.; Ilic, S.; Cominelli, F.; Rodriguez-Palacios, A. Regulation of intestinal inflammation by dietary fats. Front. Immunol. 2020, 11, 3639. [CrossRef] [PubMed] 
36. Amarasiri, W.; Dissanayake, A. Coconut fats. Ceylon Med. J. 2006, 51, 47-51. [CrossRef] [PubMed]

37. Maki, K.C.; Hasse, W.; Dicklin, M.R.; Bell, M.; Buggia, M.A.; Cassens, M.E.; Eren, F. Corn oil lowers plasma cholesterol compared with coconut oil in adults with above-desirable levels of cholesterol in a randomized crossover trial. J. Nutr. 2018, 148, 1556-1563. [CrossRef] [PubMed]

38. Marina, A.; Man, Y.C.; Amin, I. Virgin coconut oil: Emerging functional food oil. Trends Food Sci. Technol. 2009, 20, 481-487. [CrossRef]

39. Papamandjaris, A.A.; MacDougall, D.E.; Jones, P.J. Medium chain fatty acid metabolism and energy expenditure: Obesity treatment implications. Life Sci. 1998, 62, 1203-1215. [CrossRef]

40. Nagao, K.; Yanagita, T. Medium-chain fatty acids: Functional lipids for the prevention and treatment of the metabolic syndrome. Pharmacol. Res. 2010, 61, 208-212. [CrossRef]

41. Lyte, J.M.; Gabler, N.K.; Hollis, J.H. Postprandial serum endotoxin in healthy humans is modulated by dietary fat in a randomized, controlled, cross-over study. Lipids Health Dis. 2016, 15, 186. [CrossRef]

42. Remick, D.G.; Newcomb, D.E.; Bolgos, G.L.; Call, D.R. Comparison of the mortality and inflammatory response of two models of sepsis: Lipopolysaccharide vs. cecal ligation and puncture. Shock 2000, 13, 110-116. [CrossRef]

43. Zhou, H.; Yang, R.; Wang, W.; Xu, F.; Xi, Y.; Brown, R.A.; Zhang, H.; Shi, L.; Zhu, D.; Gong, D.-W. Fc-apelin fusion protein attenuates lipopolysaccharide-induced liver injury in mice. Sci. Rep. 2018, 8, 11428. [CrossRef]

44. Luo, H.; Lv, X.-D.; Wang, G.-E.; Li, Y.-F.; Kurihara, H.; He, R.-R. Anti-inflammatory effects of anthocyanins-rich extract from bilberry (Vaccinium myrtillus L.) on croton oil-induced ear edema and Propionibacterium acnes plus LPS-induced liver damage in mice. Int. J. Food Sci. Nutr. 2014, 65, 594-601. [CrossRef]

45. Nabil-Adam, A.; Shreadah, M.A. Red algae natural products for prevention of lipopolysaccharides (LPS)-induced liver and kidney inflammation and injuries. Biosci. Rep. 2021, 41, BSR20202022. [CrossRef]

46. Niu, X.; Xing, W.; Li, W.; Fan, T.; Hu, H.; Li, Y. Isofraxidin exhibited anti-inflammatory effects in vivo and inhibited TNF- $\alpha$ production in LPS-induced mouse peritoneal macrophages in vitro via the MAPK pathway. Int. Immunopharmacol. 2012, 14, 164-171. [CrossRef]

47. Tjahjono, Y.; Karnati, S.; Foe, K.; Anggara, E.; Gunawan, Y.N.; Wijaya, H.; Suyono, H.; Esar, S.Y.; Hadinugroho, W.; Wihadmadyatami, H. Anti-inflammatory activity of 2-((3-(chloromethyl) benzoyl) oxy) benzoic acid in LPS-induced rat model. Prostaglandins Other Lipid Mediat. 2021, 154, 106549. [CrossRef]

48. Son, H.-K.; Xiang, H.; Park, S.; Lee, J.; Lee, J.-J.; Jung, S.; Ha, J.-H. Partial Replacement of Dietary Fat with Polyunsaturated Fatty Acids Attenuates the Lipopolysaccharide-Induced Hepatic Inflammation in Sprague-Dawley Rats Fed a High-Fat Diet. Int. J. Environ. Res. Public Health 2021, 18, 10986. [CrossRef]

49. Lange, K.W.; Nakamura, Y.; Gosslau, A.M.; Li, S. Are there serious adverse effects of omega-3 polyunsaturated fatty acid supplements? J. Food Bioact. 2019, 7, 46. [CrossRef]

50. Nestel, P.; Shige, H.; Pomeroy, S.; Cehun, M.; Abbey, M.; Raederstorff, D. The $\mathrm{n}-3$ fatty acids eicosapentaenoic acid and docosahexaenoic acid increase systemic arterial compliance in humans. Am. J. Clin. Nutr. 2002, 76, 326-330. [CrossRef]

51. Harris, W.; Polreis, J. Measurement of the omega-3 index in dried blood spots. Ann. Clin. Lab. Res. 2016, 4, 137. [CrossRef]

52. Rosenfeld, L. Lipoprotein analysis. Early methods in the diagnosis of atherosclerosis. Arch. Pathol. Lab. Med. 1989, 113, 1101-1110.

53. Haffner, S.M.; Miettinen, H.; Stern, M.P. The homeostasis model in the San Antonio heart study. Diabetes Care 1997, $20,1087-1092$. [CrossRef]

54. Bligh, E.G.; Dyer, W.J. A rapid method of total lipid extraction and purification. Can. J. Biochem. Physiol. 1959, 37, 911-917. [CrossRef]

55. Kleiner, D.E.; Brunt, E.M.; Van Natta, M.; Behling, C.; Contos, M.J.; Cummings, O.W.; Ferrell, L.D.; Liu, Y.C.; Torbenson, M.S.; Unalp-Arida, A. Design and validation of a histological scoring system for nonalcoholic fatty liver disease. Hepatology 2005, 41, 1313-1321. [CrossRef]

56. Hariri, N.; Thibault, L. High-fat diet-induced obesity in animal models. Nutr. Res. Rev. 2010, 23, 270-299. [CrossRef]

57. Sollof, L.; Futenberg, H.; Lacko, A. Serum cholesterol esterfication in patients with coronary artery disease. Am. Heart J. 1973, 85, 153-161. [CrossRef]

58. Bray, G.A.; Krauss, R.M. Overfeeding of polyunsaturated versus saturated fatty acids reduces ectopic fat. Diabetes 2014, 63, 2222-2224. [CrossRef]

59. Moussavi, N.; Gavino, V.; Receveur, O. Could the quality of dietary fat, and not just its quantity, be related to risk of obesity? Obesity 2008, 16, 7-15. [CrossRef]

60. Herbert, D.; Franz, S.; Popkova, Y.; Anderegg, U.; Schiller, J.; Schwede, K.; Lorz, A.; Simon, J.C.; Saalbach, A. High-fat diet exacerbates early psoriatic skin inflammation independent of obesity: Saturated fatty acids as key players. J. Investig. Dermatol. 2018, 138, 1999-2009. [CrossRef]

61. Mensink, R.P. Effects of Saturated Fatty Acids on Serum Lipids and Lipoproteins: A Systematic Review and Regression Analysis; World Health Organization: Geneva, Switzerland, 2016.

62. Li, J.; Li, F.R.; Wei, D.; Jia, W.; Kang, J.X.; Stefanovic-Racic, M.; Dai, Y.; Zhao, A.Z. Endogenous w-3 Polyunsaturated Fatty Acid Production Confers Resistance to Obesity, Dyslipidemia, and Diabetes in Mice. Mol. Endocrinol. 2014, 28, 1316-1328. [CrossRef]

63. Lombardo, Y.B.; Hein, G.; Chicco, A. Metabolic syndrome: Effects of n-3 PUFAs on a model of dyslipidemia, insulin resistance and adiposity. Lipids 2007, 42, 427-437. [CrossRef] [PubMed] 
64. Huang, W.-C.; Tsai, T.-H.; Chuang, L.-T.; Li, Y.-Y.; Zouboulis, C.C.; Tsai, P.-J. Anti-bacterial and anti-inflammatory properties of capric acid against Propionibacterium acnes: A comparative study with lauric acid. J. Dermatol. Sci. 2014, 73, 232-240. [CrossRef] [PubMed]

65. Temme, E.; Mensink, R.P.; Hornstra, G. Comparison of the effects of diets enriched in lauric, palmitic, or oleic acids on serum lipids and lipoproteins in healthy women and men. Am. J. Clin. Nutr. 1996, 63, 897-903. [CrossRef] [PubMed]

66. Alves, N.F.B.; de Queiroz, T.M.; de Almeida Travassos, R.; Magnani, M.; de Andrade Braga, V. Acute treatment with lauric acid reduces blood pressure and oxidative stress in spontaneously hypertensive rats. Basic Clin. Pharmacol. Toxicol. 2017, 120, 348-353. [CrossRef]

67. Briggs, M.A.; Petersen, K.S.; Kris-Etherton, P.M. Saturated fatty acids and cardiovascular disease: Replacements for saturated fat to reduce cardiovascular risk. Healthcare 2017, 5, 29. [CrossRef]

68. Li, K.; Brennan, L.; Bloomfield, J.F.; Duff, D.J.; McNulty, B.A.; Flynn, A.; Walton, J.; Gibney, M.J.; Nugent, A.P. Adiposity associated plasma linoleic acid is related to demographic, metabolic health and haplotypes of FADS1/2 genes in Irish adults. Mol. Nutr. Food Res. 2018, 62, 1700785. [CrossRef]

69. Antonini, J.M.; Kodali, V.; Meighan, T.G.; Roach, K.A.; Roberts, J.R.; Salmen, R.; Boyce, G.R.; Zeidler-Erdely, P.C.; Kashon, M.; Erdely, A. Effect of age, high-fat diet, and rat strain on serum biomarkers and telomere length and global DNA methylation in peripheral blood mononuclear cells. Sci. Rep. 2019, 9, 1996. [CrossRef]

70. Hintze, K.J.; Benninghoff, A.D.; Cho, C.E.; Ward, R.E. Modeling the western diet for preclinical investigations. Adv. Nutr. 2018, 9 , 263-271. [CrossRef]

71. Dullo, A.; Girardier, L. Influence of dietary composition on energy expenditure during recovery of body weight in the rat: Implications for catch-up growth and obesity relapse. Metabolism 1992, 41, 1336-1342. [CrossRef]

72. Famurewa, A.C.; Akunna, G.G.; Nwafor, J.; Chukwu, O.C.; Ekeleme-Egedigwe, C.A.; Oluniran, J.N. Nephroprotective activity of virgin coconut oil on diclofenac-induced oxidative nephrotoxicity is associated with antioxidant and anti-inflammatory effects in rats. Avicenna J. Phytomed. 2020, 10, 316.

73. Hima, L.; Pratap, U.P.; Karrunanithi, S.; Ravichandran, K.A.; Vasantharekha, R.; ThyagaRajan, S. Virgin coconut oil supplementation in diet modulates immunity mediated through survival signaling pathways in rats. J. Complementary Integr. Med. 2020, 17, 1-11. [CrossRef]

74. Sreevallabhan, S.; Mohanan, R.; Jose, S.P.; Sukumaran, S.; Jagmag, T.; Tilwani, J.; Kulkarni, A. Hepatoprotective effect of essential phospholipids enriched with virgin coconut oil (Phoscoliv) on paracetamol-induced liver toxicity. J. Food Biochem. 2021, 45 , e13606. [CrossRef]

75. Alghamdi, B.S. The Effect of Short-Term Feeding of a High-Coconut Oil or High-Fat Diet on Neuroinflammation and the Performance of an Object-Place Task in Rats. Neurochem. Res. 2021, 46, 287-298. [CrossRef]

76. Khan, H.U.; Aamir, K.; Jusuf, P.R.; Sethi, G.; Sisinthy, S.P.; Ghildyal, R.; Arya, A. Lauric acid ameliorates lipopolysaccharide (LPS)-induced liver inflammation by mediating TLR4/MyD88 pathway in Sprague Dawley (SD) rats. Life Sci. 2021, $265,118750$. [CrossRef] [PubMed]

77. Adeyemi, W.J.; Olayaki, L.A.; Abdussalam, T.A.; Toriola, A.P.; Olowu, A.B.; Yakub, A.J.; Raji, A.O. Investigation of the effects of dietary modification in experimental obesity: Low dose of virgin coconut oil has a potent therapeutic value. Biomed. Pharmacother. 2020, 126, 110110. [CrossRef] [PubMed]

78. Famurewa, A.C.; Maduagwuna, E.K.; Folawiyo, A.M.; Besong, E.E.; Eteudo, A.N.; Famurewa, O.A.; Ejezie, F.E. Antioxidant, anti-inflammatory, and antiapoptotic effects of virgin coconut oil against antibiotic drug gentamicin-induced nephrotoxicity via the suppression of oxidative stress and modulation of iNOS/NF-kB/caspase-3 signaling pathway in Wistar rats. J. Food Biochem. 2020, 44, e13100. [CrossRef] [PubMed]

79. Bray, G.; Lee, M.; Bray, T. Weight gain of rats fed medium-chain triglycerides is less than rats fed long-chain triglycerides. Int. J. Obes. 1980, 4, 27-32.

80. Geliebter, A.; Torbay, N.; Bracco, E.; Hashim, S.A.; Van Itallie, T.B. Overfeeding with medium-chain triglyceride diet results in diminished deposition of fat. Am. J. Clin. Nutr. 1983, 37, 1-4. [CrossRef]

81. Cavaliere, G.; Trinchese, G.; Bergamo, P.; De Filippo, C.; Mattace Raso, G.; Gifuni, G.; Putti, R.; Moni, B.H.; Canani, R.B.; Meli, R. Polyunsaturated fatty acids attenuate diet induced obesity and insulin resistance, modulating mitochondrial respiratory uncoupling in rat skeletal muscle. PLoS ONE 2016, 11, e0149033. [CrossRef]

82. Nagy, C.; Einwallner, E. Study of in vivo glucose metabolism in high-fat diet-fed mice using oral glucose tolerance test (OGTT) and insulin tolerance test (ITT). JoVE J. Vis. Exp. 2018, e56672. [CrossRef]

83. Giknis, M.; Clifford, C. Clinical laboratory parameters for Crl: WI (Han) rats. Accel. Drug Dev. 2008, 1-14.

84. Bonora, E.; Formentini, G.; Calcaterra, F.; Lombardi, S.; Marini, F.; Zenari, L.; Saggiani, F.; Poli, M.; Perbellini, S.; Raffaelli, A. HOMA-estimated insulin resistance is an independent predictor of cardiovascular disease in type 2 diabetic subjects: Prospective data from the Verona Diabetes Complications Study. Diabetes Care 2002, 25, 1135-1141. [CrossRef]

85. Wallace, D.F. The regulation of iron absorption and homeostasis. Clin. Biochem. Rev. 2016, 37, 51.

86. Ghafoorunissa; Ibrahim, A.; Natarajan, S. Substituting dietary linoleic acid with $\alpha$-linolenic acid improves insulin sensitivity in sucrose fed rats. Biochim. Biophys. Acta (BBA)—Mol. Cell Biol. Lipids 2005, 1733, 67-75. [CrossRef]

87. Han, J.; Hamilton, J.A.; Kirkland, J.L.; Corkey, B.E.; Guo, W. Medium-chain oil reduces fat mass and down-regulates expression of adipogenic genes in rats. Obes. Res. 2003, 11, 734-744. [CrossRef] 
88. Wein, S.; Wolffram, S.; Schrezenmeir, J.; Gašperiková, D.; Klimeš, I.; Šeböková, E. Medium-chain fatty acids ameliorate insulin resistance caused by high-fat diets in rats. Diabetes/Metab. Res. Rev. 2009, 25, 185-194. [CrossRef]

89. Liang, H.; Hussey, S.E.; Sanchez-Avila, A.; Tantiwong, P.; Musi, N. Effect of lipopolysaccharide on inflammation and insulin action in human muscle. PLoS ONE 2013, 8, e63983. [CrossRef]

90. Bosomworth, N.J. Approach to identifying and managing atherogenic dyslipidemia: A metabolic consequence of obesity and diabetes. Can. Fam. Physician 2013, 59, 1169-1180.

91. Choi, G.-h.; Jung, Y.-s.; Shin, H.-c. The effects of haedoksamul-tang on oxidative stress and hyperlipidemia in LPS-induced ICR mouse. J. Korean Med. 2016, 37, 77-89. [CrossRef]

92. Lassenius, M.I.; Pietiläinen, K.H.; Kaartinen, K.; Pussinen, P.J.; Syrjänen, J.; Forsblom, C.; Pörsti, I.; Rissanen, A.; Kaprio, J.; Mustonen, J. Bacterial endotoxin activity in human serum is associated with dyslipidemia, insulin resistance, obesity, and chronic inflammation. Diabetes Care 2011, 34, 1809-1815. [CrossRef]

93. Wahby, M.M.; Yacout, G.; Kandeel, K.; Awad, D. LPS-induced oxidative inflammation and hyperlipidemia in male rats: The protective role of Origanum majorana extract. Beni-Suef Univ. J. Basic Appl. Sci. 2015, 4, 291-298. [CrossRef]

94. Yu, S.; Wen, Y.; Li, J.; Zhang, H.; Liu, Y. Prenatal lipopolysaccharide exposure promotes dyslipidemia in the male offspring rats. Front. Physiol. 2018, 9, 542. [CrossRef]

95. Famurewa, A.C.; Ekeleme-Egedigwe, C.A.; Nwali, S.C.; Agbo, N.N.; Obi, J.N.; Ezechukwu, G.C. Dietary supplementation with virgin coconut oil improves lipid profile and hepatic antioxidant status and has potential benefits on cardiovascular risk indices in normal rats. J. Diet. Suppl. 2018, 15, 330-342. [CrossRef]

96. Nevin, K.; Rajamohan, T. Beneficial effects of virgin coconut oil on lipid parameters and in vitro LDL oxidation. Clin. Biochem. 2004, 37, 830-835. [CrossRef]

97. Speliotes, E.K.; Balakrishnan, M.; Friedman, L.S.; Corey, K.E. Treatment of dyslipidemia in common liver diseases. Clin. Gastroenterol. Hepatol. 2018, 16, 1189-1196. [CrossRef]

98. Kwon, H.-K.; Patra, M.C.; Shin, H.-J.; Gui, X.; Achek, A.; Panneerselvam, S.; Kim, D.-J.; Song, S.-J.; Hong, R.; Kim, K.S. A cellpenetrating peptide blocks Toll-like receptor-mediated downstream signaling and ameliorates autoimmune and inflammatory diseases in mice. Exp. Mol. Med. 2019, 51, 1-19. [CrossRef]

99. Lu, W.; Li, S.; Li, J.; Wang, J.; Zhang, R.; Zhou, Y.; Yin, Q.; Zheng, Y.; Wang, F.; Xia, Y. Effects of omega-3 fatty acid in nonalcoholic fatty liver disease: A meta-analysis. Gastroenterol. Res. Pract. 2016, 2016, 1459790. [CrossRef]

100. Shapiro, H.; Tehilla, M.; Attal-Singer, J.; Bruck, R.; Luzzatti, R.; Singer, P. The therapeutic potential of long-chain omega-3 fatty acids in nonalcoholic fatty liver disease. Clin. Nutr. 2011, 30, 6-19. [CrossRef]

101. Spadaro, L.; Magliocco, O.; Spampinato, D.; Piro, S.; Oliveri, C.; Alagona, C.; Papa, G.; Rabuazzo, A.; Purrello, F. Effects of n-3 polyunsaturated fatty acids in subjects with nonalcoholic fatty liver disease. Dig. Liver Dis. 2008, 40, 194-199. [CrossRef]

102. Liu, L.; Mei, M.; Yang, S.; Li, Q. Roles of chronic low-grade inflammation in the development of ectopic fat deposition. Mediat. Inflamm. 2014, 2014, 418185. [CrossRef] [PubMed]

103. Nishimura, S.; Manabe, I.; Nagasaki, M.; Eto, K.; Yamashita, H.; Ohsugi, M.; Otsu, M.; Hara, K.; Ueki, K.; Sugiura, S. CD8+ effector T cells contribute to macrophage recruitment and adipose tissue inflammation in obesity. Nat. Med. 2009, 15, 914-920. [CrossRef] [PubMed]

104. Altintas, M.M.; Rossetti, M.A.; Nayer, B.; Puig, A.; Zagallo, P.; Ortega, L.M.; Johnson, K.B.; McNamara, G.; Reiser, J.; Mendez, A.J. Apoptosis, mastocytosis, and diminished adipocytokine gene expression accompany reduced epididymal fat mass in long-standing diet-induced obese mice. Lipids Health Dis. 2011, 10, 198. [CrossRef] [PubMed]

105. Mulder, P.; Morrison, M.; Wielinga, P.; Van Duyvenvoorde, W.; Kooistra, T.; Kleemann, R. Surgical removal of inflamed epididymal white adipose tissue attenuates the development of non-alcoholic steatohepatitis in obesity. Int. J. Obes. 2016, 40, 675-684. [CrossRef] [PubMed]

106. Lafontan, M. Adipose tissue and adipocyte dysregulation. Diabetes Metab. 2014, 40, 16-28. [CrossRef]

107. Liang, W.; Tonini, G.; Mulder, P.; Kelder, T.; van Erk, M.; van den Hoek, A.M.; Mariman, R.; Wielinga, P.Y.; Baccini, M.; Kooistra, T. Coordinated and interactive expression of genes of lipid metabolism and inflammation in adipose tissue and liver during metabolic overload. PLoS ONE 2013, 8, e75290. [CrossRef]

108. Duval, C.; Thissen, U.; Keshtkar, S.; Accart, B.; Stienstra, R.; Boekschoten, M.V.; Roskams, T.; Kersten, S.; Müller, M. Adipose tissue dysfunction signals progression of hepatic steatosis towards nonalcoholic steatohepatitis in C57BL/6 mice. Diabetes 2010, 59, 3181-3191. [CrossRef]

109. Gart, E.; Salic, K.; Morrison, M.C.; Caspers, M.; van Duyvenvoorde, W.; Heijnk, M.; Giera, M.; Bobeldijk-Pastorova, I.; Keijer, J.; Storsve, A.B. Krill oil treatment increases distinct pufas and oxylipins in adipose tissue and liver and attenuates obesity-associated inflammation via direct and indirect mechanisms. Nutrients 2021, 13, 2836. [CrossRef]

110. Awada, M.; Meynier, A.; Soulage, C.O.; Hadji, L.; Géloën, A.; Viau, M.; Ribourg, L.; Benoit, B.; Debard, C.; Guichardant, M. n-3 PUFA added to high-fat diets affect differently adiposity and inflammation when carried by phospholipids or triacylglycerols in mice. Nutr. Metab. 2013, 10, 23. [CrossRef]

111. Saraswathi, V.; Kumar, N.; Gopal, T.; Bhatt, S.; Ai, W.; Ma, C.; Talmon, G.A.; Desouza, C. Lauric acid versus palmitic acid: Effects on adipose tissue inflammation, insulin resistance, and non-alcoholic fatty liver disease in obesity. Biology 2020, 9, 346. [CrossRef] 
112. Ströher, D.J.; de Oliveira, M.F.; Martinez-Oliveira, P.; Pilar, B.C.; Cattelan, M.D.P.; Rodrigues, E.; Bertolin, K.; Gonçalves, P.B.D.; Piccoli, J.d.C.E.; Manfredini, V. Virgin coconut oil associated with high-fat diet induces metabolic dysfunctions, adipose inflammation, and hepatic lipid accumulation. J. Med. Food 2020, 23, 689-698. [CrossRef]

113. Achek, A.; Yesudhas, D.; Choi, S. Toll-like receptors: Promising therapeutic targets for inflammatory diseases. Arch. Pharm. Res. 2016, 39, 1032-1049. [CrossRef]

114. O'neill, L.A.; Golenbock, D.; Bowie, A.G. The history of Toll-like receptors-redefining innate immunity. Nat. Rev. Immunol. 2013, 13, 453-460. [CrossRef]

115. Zuany-Amorim, C.; Hastewell, J.; Walker, C. Toll-like receptors as potential therapeutic targets for multiple diseases. Nat. Rev. Drug Discov. 2002, 1, 797-807. [CrossRef]

116. Laugerette, F.; Vors, C.; Peretti, N.; Michalski, M.-C. Complex links between dietary lipids, endogenous endotoxins and metabolic inflammation. Biochimie 2011, 93, 39-45. [CrossRef]

117. Raetzsch, C.F.; Brooks, N.L.; Alderman, J.M.; Moore, K.S.; Hosick, P.A.; Klebanov, S.; Akira, S.; Bear, J.E.; Baldwin, A.S.; Mackman, N. Lipopolysaccharide inhibition of glucose production through the Toll-like receptor-4, myeloid differentiation factor 88 , and nuclear factor kb pathway. Hepatology 2009, 50, 592-600. [CrossRef]

118. Imajo, K.; Fujita, K.; Yoneda, M.; Nozaki, Y.; Ogawa, Y.; Shinohara, Y.; Kato, S.; Mawatari, H.; Shibata, W.; Kitani, H. Hyperresponsivity to low-dose endotoxin during progression to nonalcoholic steatohepatitis is regulated by leptin-mediated signaling. Cell Metab. 2012, 16, 44-54. [CrossRef]

119. Tesfay, M.; Goldkamp, W.J.; Neuschwander-Tetri, B.A. NASH: The emerging most common form of chronic liver disease. Mo. Med. 2018, 115, 225.

120. Wellen, K.E.; Hotamisligil, G.S. Inflammation, stress, and diabetes. J. Clin. Investig. 2005, 115, 1111-1119. [CrossRef]

121. Fang, Y.-L.; Chen, H.; Wang, C.-L.; Liang, L. Pathogenesis of non-alcoholic fatty liver disease in children and adolescence: From "two hit theory" to "multiple hit model". World J. Gastroenterol. 2018, 24, 2974. [CrossRef]

122. Alwayn, I.P.; Gura, K.; Nosé, V.; Zausche, B.; Javid, P.; Garza, J.; Verbesey, J.; Voss, S.; Ollero, M.; Andersson, C. Omega-3 fatty acid supplementation prevents hepatic steatosis in a murine model of nonalcoholic fatty liver disease. Pediatric Res. 2005, 57, 445-452. [CrossRef]

123. Liu, M.; Montgomery, M.K.; Fiveash, C.E.; Osborne, B.; Cooney, G.J.; Bell-Anderson, K.; Turner, N. PPAR $\alpha$-independent actions of omega-3 PUFAs contribute to their beneficial effects on adiposity and glucose homeostasis. Sci. Rep. 2015, 4, 5538. [CrossRef]

124. Chung, K.W.; Kim, K.M.; Choi, Y.J.; An, H.J.; Lee, B.; Kim, D.H.; Lee, E.K.; Im, E.; Lee, J.; Im, D.S. The critical role played by endotoxin-induced liver autophagy in the maintenance of lipid metabolism during sepsis. Autophagy 2017, 13, 1113-1129. [CrossRef] 